\title{
Techno-economic analysis of polygeneration systems based on catalytic hydropyrolysis for the production of bio-oil and fuels
}

\author{
Nguyen, Tuong-Van; Clausen, Lasse Røngaard
}

\section{Published in:}

Energy Conversion and Management

Link to article, DOI:

10.1016/j.enconman.2019.01.070

Publication date:

2019

Document Version

Peer reviewed version

Link back to DTU Orbit

Citation (APA):

Nguyen, T-V., \& Clausen, L. R. (2019). Techno-economic analysis of polygeneration systems based on catalytic hydropyrolysis for the production of bio-oil and fuels. Energy Conversion and Management, 184, 539-558. https://doi.org/10.1016/j.enconman.2019.01.070

\section{General rights}

Copyright and moral rights for the publications made accessible in the public portal are retained by the authors and/or other copyright owners and it is a condition of accessing publications that users recognise and abide by the legal requirements associated with these rights.

- Users may download and print one copy of any publication from the public portal for the purpose of private study or research.

- You may not further distribute the material or use it for any profit-making activity or commercial gain

- You may freely distribute the URL identifying the publication in the public portal 


\title{
Techno-economic analysis of polygeneration systems based on catalytic hydropyrolysis for the production of bio-oil and fuels
}

\author{
Tuong-Van Nguyen ${ }^{\mathrm{a}, *}$, Lasse Røngaard Clausen ${ }^{\mathrm{a}}$ \\ ${ }^{a}$ Section of Thermal Energy, Department of Mechanical Engineering, Technical University of Denmark, \\ Building 403, Nils Koppels Allé, 2800 Kongens Lyngby, Denmark
}

\begin{abstract}
The present paper presents an assessment of the techno-economic performance of novel polygeneration concepts for bio-oil production. They are based on catalytic hydropyrolysis and hydrodeoxygenation, and can be integrated with other processes for co-production of synthetic natural gas, molecular hydrogen and methanol. Thirteen system layouts were evaluated considering different technological alternatives and process pathways. Firstly, detailed thermodynamic and economic models were developed to calculate and compare the energy demands, capital and production costs of all plants, given a biomass input of 2000 dry metric tonnes per day. Sensitivity analyses using local approaches, Morris screening and multi-variable linear regression tools were then conducted to identify the essential parameters. Finally, uncertainty analyses were performed to estimate the minimum selling price of bio-oil for each case. The results show that the total capital costs range between $\$ 180$ and $\$ 620$ million, for a production cost between $\$ 17$ and $\$ 24$ per GJ of fuel. The feedstock and electricity costs represent the greatest share (up to $60 \%$ together) followed by the annualised investment costs (up to $18 \%$ ). The sensitivity analyses suggest that the plant profitability is mostly impacted by the bio-oil yield, by-product characteristics, electrolysis costs, wood and power prices. The uncertainty analysis, through Monte-Carlo simulations, demonstrates that the minimum fuel selling prices may vary from $\$-3$ to $\$ 240$ per GJ. The most promising layouts are those with SNG and $\mathrm{H}_{2}$ production, whilst the riskiest ones are those with electrolysis.
\end{abstract}

Keywords: Biomass, green fuels, hydropyrolysis, hydrodeoxygenation, techno-economic analysis

*Principal corresponding author. Tel.: +45 4525 4129

Email addresses: tungu@mek.dtu.dk (Tuong-Van Nguyen), lrc@mek.dtu.dk (Lasse Røngaard Clausen) 


\begin{tabular}{|c|c|c|c|}
\hline \multicolumn{4}{|c|}{ Nomenclature } \\
\hline$C_{\mathrm{ACR}}$ & Annual capital repayment, $\$ /$ year & AEC & Alkaline Electrolyser Cell \\
\hline$C_{\mathrm{BM}, \mathrm{ref}}$ & Bare module cost (reference size), $\$$ & \multicolumn{2}{|c|}{ DCFROR Discounted cash flow rate of return } \\
\hline$C_{\mathrm{BM}}$ & Bare module cost (real conditions), $\$$ & DEPG & Dimethyl Ether of Polyethylene Glycol \\
\hline$C_{\mathrm{BM}}^{0}$ & Bare module cost (base case conditions), $\$$ & DME & Dimethylether \\
\hline$C_{\mathrm{FP}}$ & Fuel production cost, $\$ / \mathrm{MWh}$ & DNA & Dynamic Networks Analysis \\
\hline$C_{\mathrm{GR}}$ & Grassroot costs, $\$$ & EOS & Equation of State \\
\hline$C_{\mathrm{OL}}$ & Operating labour costs, $\$ /$ year & FT & Fischer-Tropsch \\
\hline$C_{\mathrm{OM}}$ & Operating and maintenance costs, $\$ /$ year & HDO & Hydrodeoxygenation \\
\hline$C_{\mathrm{PC}}$ & Purchased equipment cost, $\$$ & HHV & Higher Heating Value \\
\hline$E$ & Elementary effect & LHS & Latin Hypercube Sampling \\
\hline$N$ & Number of samples (Monte-Carlo analysis) & LHV & Lower Heating Value \\
\hline$N_{\mathrm{OL}}$ & Number of operators & MEA & Monoethanolamine \\
\hline$R^{2}$ & Coefficient of determination & $\mathrm{MeOH}$ & Methanol \\
\hline$S$ & Size parameter (installed size) & MFSP & Minimum fuel selling price \\
\hline$S E$ & Standardised elementary effect & MSI & Marshall Swift Index (current year) \\
\hline$S_{\text {ref }}$ & Size parameter (reference size) & $\mathrm{MSI}_{\mathrm{ref}}$ & Marshall Swift Index (reference year) \\
\hline$X_{C}$ & Carbon conversion efficiency & NPV & Net present value \\
\hline$\dot{V}$ & Volume flowrate, $\mathrm{m}^{3} / \mathrm{s}$ & NRTL & Non-Random Two-Liquids \\
\hline$\dot{m}$ & Mass flowrate, $\mathrm{m} / \mathrm{s}$ & OAT & One-factor-at-a-time \\
\hline$a, b$ & Shape parameters (beta distribution) & $\mathrm{PC}$ & Perturbated Chain \\
\hline$b$ & Non-standardized regression coefficient & PSA & Pressure Swing Adsorption \\
\hline$b_{1}, b_{2}$ & Equipment-based factors & SAFT & Statistical Associating Fluid Theory \\
\hline$d$ & Reactor diameter, $\mathrm{m}$ & SNG & Synthetic Natural Gas \\
\hline$f_{m}$ & Material-based factor & SOEC & Solid Oxide Electrolyser Cell \\
\hline$f_{p}$ & Pressured-based factor & $\mathrm{SRC}$ & Standardised regression coefficient \\
\hline$h$ & Reactor height, $\mathrm{m}$ & WGS & Water Gas Shift \\
\hline$h_{0}$ & Reactor height factor, $\mathrm{m}\left(\mathrm{m}^{3} \cdot \mathrm{s}^{-1}\right)^{-0.188}$ & \multicolumn{2}{|c|}{ Greek letters } \\
\hline$i$ & Inflation rate & $\alpha$ & Cost capacity exponent \\
\hline$k$ & Number of variables (uncertainty analysis) & $\alpha_{1}$ & Contingencies and fees factor \\
\hline \multicolumn{2}{|c|}{$k_{1}, k_{2}, k_{3}$ Equipment-based factors } & $\alpha_{2}$ & Auxiliary facilities and site development factor \\
\hline$p$ & Number of levels (Morris screening) & $\beta$ & Beta coefficient \\
\hline$r$ & Discount rate (profitability analysis) & $\Delta h^{0}$ & Lower heating value, $\mathrm{J} / \mathrm{kg}$ \\
\hline$r$ & Number of replications (Morris screening) & $\eta$ & Energy efficiency \\
\hline$r_{\text {eff }}$ & Effective discount rate & $\mu$ & Mean value \\
\hline$u_{m}$ & Mean velocity, $\mathrm{m} / \mathrm{s}$ & $\mu^{*}$ & Mean of the absolute values of the distribution \\
\hline$x$ & Mass fraction, $\mathrm{kg} / \mathrm{kg}$ & $\sigma$ & Standard deviation \\
\hline \multicolumn{2}{|c|}{ Abbreviations } & $\varepsilon$ & Regression error \\
\hline
\end{tabular}




\section{Introduction}

The conversion of biomass into high-value chemicals, fuels, power and heat has gained attention in the last decades as a mean to reduce our consumption of fossil fuels and carbon footprint. At present, the transportation sector relies heavily on petroleum products and is responsible for around a quarter of the European Union's (EU) greenhouse gas emissions. It is the only major sector where the current emissions keep rising, being far above the 1990-levels [1]. Action is therefore required to reach the mitigation targets set in the Paris climate agreement [2] and in the last EU white papers and policy frameworks [3]. A $60 \%$ reduction from the 1990 levels by 2050 is currently targeted, and the deployment of new fuel technologies such as biofuels can play a valuable role towards the decarbonisation of this sector.

However, aside the case of sugarcane-based ethanol in Brazil, biofuels may not be competitive without substantial government support (e.g. financial mechanisms such as tax reduction) for low (under $70 \$ /$ barrel) oil prices [4]. The cost of biofuels depends strongly on the feedstock price, and the generation of multiple products from biomass (polygeneration) can offer higher conversion efficiency, feedstock flexibility, and lower production costs. Polygeneration systems can be a step towards more competitive biomass-derived fuels [5].

Pyrolysis is a thermal and oxygen-free process for converting biomass into a liquid product named biooil. It usually has undesirable properties: high oxygen and water contents, low heating value, high acidity, high viscosity, corrosivity, non-miscibility with conventional fossil fuels, and short shelf life. Upgrading via hydrotreatment is necessary to remove the oxygen content and produce a diesel- or gasoline-like fuel. In addition, pyrolysis results in the production of a non-condensable gas mainly composed of carbon monoxide (CO) and dioxide $\left(\mathrm{CO}_{2}\right)$ and of a carbon-rich solid termed bio-char. The technical feasibility of combining pyrolysis and hydrodeoxygenation (HDO) in a catalytic hydropyrolysis process at high hydrogen pressures was demonstrated in recent studies [6,7]. Biomass is converted into water vapour and carbon oxides, and undesirable reactions such as polymerization and coking are minimized. The resulting liquid product has therefore a much higher energy density than the bio-oil from conventional pyrolysis systems, is more stable and presents better thermo-chemical characteristics [8]. The use of a catalyst is one of the most common upgrading methods for improving the bio-oil quality. It can improve the cracking reactions of the highweight compounds in pyrolysis oils, reduce the formation of carboxylic acids and promote the generation of hydrocarbons [9].

The present work focuses on the feasibility of catalytic hydropyrolysis coupled with deep hydrodeoxygenation in an ex situ design (i.e. two distinct reactors), as termed in the literature [7]. Biomass is first converted into hydrocarbons and pyrolysis vapour via fast hydropyrolysis in a catalytic reactor. The produced vapours are then upgraded to hydrocarbons by HDO in a catalytic packed bed. Hydropyrolysis and deep HDO take place at different operating conditions. This approach was discussed and demonstrated in the Purdue [10] and GTI [11] patents. Venkatakrishnan et al.[12] at Purdue University developed the H2Bioil system: fast hydropyrolysis takes place at $480-580^{\circ} \mathrm{C}$ and hydrodeoxygenation at $300-375^{\circ} \mathrm{C}$. The Gas Technology Institute developed the $\mathrm{IH}^{2}$ system: fast hydropyrolysis also takes place in presence of a catalyst and with similar temperature and pressure ranges as in Venkatakrishnan et al.[12]. Various system layouts for converting the non-condensable gases into valuable chemicals and for integrating renewable energy sources were also discussed.

The first studies on the production cost of bio-oil via fast pyrolysis date from the late 90s, but few actually discussed the upgrading cost from bio-oil to a transportation fuel. The large differences in assumptions for the biomass cost, plant capacity and process technologies resulted in very different estimates of the biooil cost. They ranged between $\$ 0.41$ and $\$ 2.46$ per gallon, and the capital costs varied from $\$ 37$ [13] to $\$ 143$ million [14] for a plant capacity of 1000 tonnes per day. More recently, Wright et al.[15] performed a techno-economic analysis of the fast pyrolysis of corn stover to bio-oil with subsequent upgrading, based on two scenarios for the production and generation of hydrogen. The authors estimated a fuel product value of $\$ 3.09$ per gallon of gasoline equivalent (gge), i.e. $\$ 0.82$ per litre, for the first scenario. This value was highly sensitive to the biomass conversion yield and feedstock price. However, they also stressed the early stage of development of such processes. The capital cost of such a plant was estimated to $\$ 287$ million if all technologies to be installed were mature ( $n$th plant assumption), and to $\$ 911$ million if the process steps were not demonstrated commercially (pioneer plant analysis). Brown et al.[16] presented an estimate of 
$\$ 2.57$ per gge ( $\$ 0.68$ per litre), using updated economic parameters, but pointed out the sensitivity of this number to process conditions. The biomass conversion plants were assumed to process 2000 dry tonnes per day in both cases.

Marker et al.[17] demonstrated the viability of the $\mathrm{IH}^{2}$ system, presenting the pilot plant data, and Tan et al.[18] presented a subsequent techno-economic analysis. They found a minimum fuel selling price (MFSP) of $\$ 1.68$ per gge. This represented a significant reduction compared to previous studies, which results from the on-site production of hydrogen. The total estimated capital cost is $\$ 264$ million for a processing capacity of 2000 dry metric tonnes per day ( $n$th plant assumption). The hydrogen production plant (reforming) was found to be the most expensive process area, followed by the hydropyrolysis and hydroconversion reactors. Li et al.[19] carried out a techno-economic and uncertainty analysis of in situ and ex situ designs. The selling prices were between $\$ 4.20$ and $\$ 4.27$ per gallon, and ex situ systems have a lower uncertainty. As stressed, the large differences across these works were likely due to differences in system configurations, economic and technical assumptions. Direct comparisons of the values found for the minimum selling price of bio-oil are therefore inconsistent. There is though a global consensus that the feedstock price, project investment and product yields are some of the most influential parameters on the plant profitability.

The main challenges for a future development of such systems are to: (i) demonstrate the feasibility and optimise the set-up of the combined hydropyrolysis - hydrodeoxygenation process; (ii) develop the most suitable catalyst formulations to prevent undesirable reactions; and (iii) analyse the technical and economical viability of various polygeneration plants based on this biofuel production concept. The present paper aims at addressing some of these gaps, and the work novelty lies in a systematic technoeconomic comparison of hydropyrolysis - hydrodeoxygenation systems, accounting for possible uncertainties in the process and economic conditions.

Thirteen different biorefineries based on catalytic hydropyrolysis and hydrodeoxygenation were designed and modelled in details. The integration of electrolysis is considered for some of these layouts. A greater fuel output is expected, because all the gases recovered from the hydropyrolysis - hydrodeoxygenation reactors can be processed to generate additional fuels instead of being partly used to sustain the hydrogen demand on-site. In addition, this presents the advantage of using excess electricity from e.g. wind mills for generating biofuels, decarbonising the transportation sector. An economic analysis was performed following a $n$th plant approach, i.e. the technologies and processes are well-known and ready to be implemented, to calculate the total capital costs and minimum fuel selling prices. Sensitivity and uncertainty analyses were conducted for each case to assess the impact of various technical and economic parameters (e.g. product yield, lifetime, power price, etc.) on the profitability of these plants.

\section{Design of the biorefineries}

\subsection{Biorefinery layouts}

The layout of the biorefineries investigated in this paper is presented in a previous study by the authors [20], but a short description is given for ease of reading. The main processes, common to all plant designs, are the feedstock preparation, the hydropyrolysis and hydrodeoxygenation, and the gas-liquids separation. Biomass is first fed into the hydropyrolysis reactor in a hydrogen-rich environment and at high pressure. The produced vapours are then upgraded in the hydrodeoxygenation at lower temperature. Four phases are generated and separated: (i) an organic phase composed of hydrocarbons $\left(\mathrm{C}_{4}^{+}\right)$with diesel- or gasoline-like properties, (ii) an aqueous phase, (iii) a solid phase of char and ash, and (iv) a gaseous mixture with light-weight hydrocarbons $\left(\mathrm{C}_{1}-\mathrm{C}_{3}\right)$, carbon oxides $\left(\mathrm{CO}\right.$ and $\left.\mathrm{CO}_{2}\right)$, hydrogen and water vapour. Unlike conventional pyrolysis oil, the produced bio-oil from this process is not soluble in water, implying that the two liquid phases can be easily separated into a carbon-free water and a near-ready fuel.

Alternative layouts can be designed building on this process concept. The first option, presented in the Gas Technology Institute patent [11], is to ensure that the overall polygeneration system is self-sustaining, i.e. does not require any external input other than biomass. The second option is to implement other process units to maximise the gas-liquid yield by valorising the bio-char generated in the hydropyrolysis process. The third possibility is to co-produce fuels such as SNG or $\mathrm{MeOH}$. All the possible process pathways, as well 
as the different technological options of each step, are assembled and summarised in a process superstructure (Figure 1). Electricity required for e.g. electrolysis or reforming heating is assumed to come from renewable energy sources such as wind energy, as the vision is to ease the penetration of renewable energies into the transportation sector.

The main differences between the biorefinery layouts (Table 1) are:

- the type of fuel generated aside bio-oil ( $\mathrm{SNG}, \mathrm{H}_{2}, \mathrm{MeOH}$ or none);

- the use of char, either for syngas production (gasification) or high-temperature heating (combustion);

- the source of hydrogen for the hydropyrolysis reactors (steam electrolysis or reforming of light gases)

Each design is therefore unique with regards to the energy demands (e.g. power, heating and cooling), component sizes (e.g. capacity) and processing routes (e.g. methanation, synthesis, treatment). These layouts were investigated and compared because they are different in terms of by-product, each possibly of interest on the market, and include processes that are already mature (absorption) and others (electrolysis) that can be used to ease penetration of renewable energies in the industry. The suffixes ' $\mathrm{CA}$ ' and 'PA' indicate whether chemical or physical absorption is implemented. The suffixes 'SE' and 'AE' stand for solid oxide and alkaline electrolysis. For example, a polygeneration system with SNG production, hydrogen production by reforming and char gasification is denoted SNG-R-G. It can either be designed with a chemical absorption unit ('SNG-R-G-CA') or a physical one ('SNG-R-G-PA').

Table 1: List of investigated configurations

\begin{tabular}{cccccc}
\hline Layout & Fuel & $\mathrm{H}_{2}$-production & Char use & Upgrading & Reformer heating \\
\hline B $^{\mathrm{a}}$ & none & Reforming & - & PSA & Gas combustion \\
SNG-R ${ }^{\mathrm{b}, \mathrm{c}}$ & $\mathrm{SNG}$ & Reforming & - & PSA & Electrical \\
SNG-R-C & SNG & Reforming & Combustion & PSA & Char combustion \\
SNG-R-G & SNG & Reforming & Gasification & PSA & Electrical \\
SNG-E & SNG & Electrolysis & - & - & - \\
SNG-E-G & SNG & Electrolysis & Gasification & - & - \\
H2-R-G & $\mathrm{H}_{2}$ & Reforming & Gasification & PSA & Electrical \\
MeOH-R-G & $\mathrm{MeOH}$ & Reforming & Gasification & PSA & Electrical \\
MeOH-E-G & MeOH & Electrolysis & Gasification & PSA & Electrical \\
\hline
\end{tabular}

a ' $\mathrm{B}$ ' is the standard system layout, with bio-oil generation, hydrogen production from reforming of the light gases and $\mathrm{CO}_{2}$-separation with chemical absorption.

b The prefixes 'SNG', 'H2' and 'MeOH' indicate which chemical fuel is co-produced.

' The prefixes ' $R$ ' and ' $E$ ' denote whether the hydrogen required in the pyrolysis process is generated by reforming of the light gases or by water/steam electrolysis.

d The prefixes ' $\mathrm{C}$ ' and ' $\mathrm{G}$ ' stand for combustion and gasification of char. These thirteen layouts can be further subdivided depending on the technologies used for performing specific process operations, such as $\mathrm{CO}_{2}$-capture and electrolysis.

The models developed to compare the polygeneration concepts were developed and presented in Nguyen and Clausen[20]. The aim was to compute mass and energy balances for further component sizing and economic evaluations. The biorefinery plants were modelled using the in-house software Dynamic Networks Analysis (DNA) [21] and Aspen Plus version 7.2 [22], considering maple woods as feedstock [23] (Table 2).

The hydropyrolysis and hydrodeoxygenation steps were modelled as a black-box reactor with the yield factors for the bio-oil (28\%), char (9\%), water $(36 \%)$ and non-condensable products $(31 \%)$ taken from the results of the $\mathrm{IH}^{2}$ project, experiment $5 / 25$.

\subsection{Hydrogen production}

Hydrogen required for the hydrodeoxygenation reactions is produced either externally (water or steam electrolysis) or internally, through conversion of the non-condensable gases (gas upgrading, steam methane 


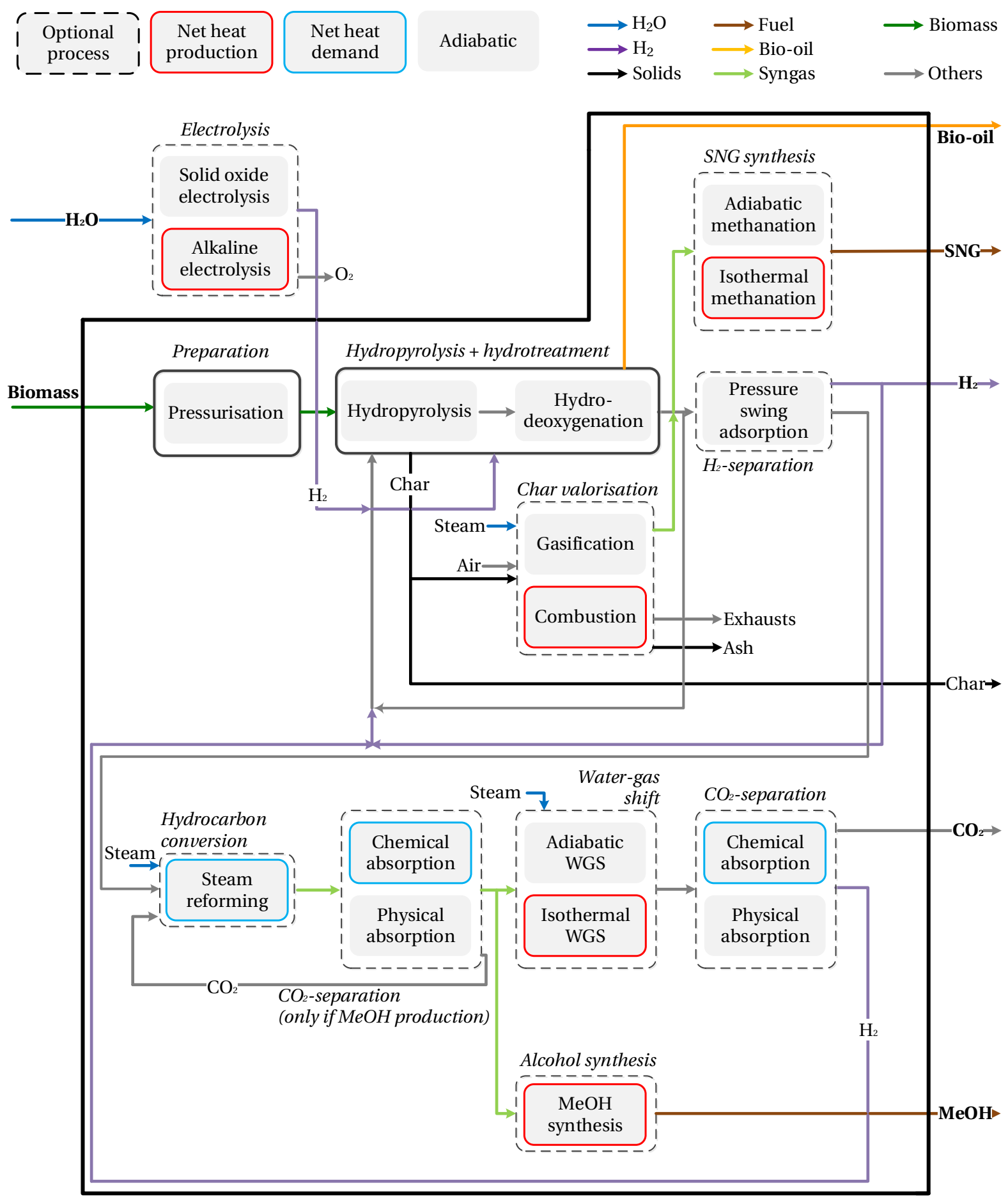

Figure 1: Superstructure of the polygeneration system for production of bio-oil, $\mathrm{SNG}, \mathrm{H}_{2}$ and $\mathrm{MeOH}$ through hydropyrolysis and hydrodeoxygenation. 
Table 2: General parameters for the process modelling

\begin{tabular}{ll}
\hline Feedstock & 2000 tonnes per day \\
Elemental analysis (dry) & \\
C & $49.2 \%$ \\
O & $43.3 \%$ \\
H & $6.3 \%$ \\
N & $0.11 \%$ \\
Ash & $1.1 \%$ \\
HHV - dry & $18.9 \mathrm{MJ} / \mathrm{kg}$ \\
LHV - dry & $17.5 \mathrm{MJ} / \mathrm{kg}$ \\
\hline
\end{tabular}

reforming, water-gas shift and $\mathrm{CO}_{2}$-removal). In the first case, electrolysis is either carried out at low temperatures by converting water in alkaline electrolyte cells (AEC) or at high temperatures by processing steam in solid oxide electrolysis cells (SOEC) [24-26]. Operating temperatures of $80^{\circ} \mathrm{C}$ and $750{ }^{\circ} \mathrm{C}$ were selected for low- and high-temperature electrolysis, with a given efficiency of $64 \%$ and $95 \%$ [25,26].

In the second case, the non-condensable gases are upgraded by undergoing pressure-swing-adsorption (PSA) at 22 bar (feed) to 1.1 bar (purge) for producing a high-purity (99.99\%) hydrogen stream which is directly recirculated into the pyrolysis reactor. The adsorbed gas is reformed at 5 bar and $900{ }^{\circ} \mathrm{C}$ and enters a two-step $\left(350^{\circ} \mathrm{C}\right.$ and $\left.200^{\circ} \mathrm{C}\right)$ water-gas-shift unit - thermodynamic equilibrium is assumed at the reactor outlet $[27,28] . \mathrm{CO}_{2}$ is then removed in a chemical absorption unit (5 bar) with monoethanolamine (MEA) or in a high-pressure (22 bar) physical absorption module with dimethyl ethers of polyethylene glycols (DPEG)[29]. Chemical equilibrium cannot be assumed for the chemical absorption unit, and the reaction kinetics were considered explicitly using a rate-based model. It was based on the electrolyte NRTL method [30] (liquid phase) and the Redlich-Kwong equation of state (EOS) [31] (vapour phase) for MEA absorption. The physical unit with DPEG absorption was simulated using the PC-SAFT equation of state [32].

\subsection{Char valorisation}

The produced bio-char has a high carbon content and can be exploited in two main ways, either through combustion, if high-temperature heat is required (e.g. steam reforming) or through steam hydrogasification, if a higher yield of synthesis gas is desired. Combustion is carried out at atmospheric conditions at $1200^{\circ} \mathrm{C}$, considering air preheating and assuming total reactions. Gasification is assumed to reach an equilibrium temperature of $725^{\circ} \mathrm{C}$ with a constant carbon conversion of $90 \%$ [33]. Steam is used as gasification agent the use of oxygen is disregarded to avoid an air separation plant and large $\mathrm{CO}_{2}$-removal processes.

\subsection{Fuel synthesis}

In addition, fuels such as $\mathrm{SNG}$ and $\mathrm{MeOH}$ can be co-produced by implementing methane or methanol synthesis processes to convert the non-condensable gases recovered from the phase separation step. These gases already have a high content of light hydrocarbons $\left(\mathrm{CH}_{4}\right.$ and $\left.\mathrm{C}_{2} \mathrm{H}_{6}\right)$ and only conversion of the carbon oxides into methane is required to generate a high-quality SNG. Methanation is assumed to be carried out from $250^{\circ} \mathrm{C}$ to $300^{\circ} \mathrm{C}$ and to reach thermodynamic equilibrium at the outlet of the reactor [34]. Methanol production requires carbon oxides and hydrogen $[35,36]$ and is implemented after the reforming and $\mathrm{CO}_{2}-$ removal modules. The synthesis process takes place at $96 \mathrm{bar}$ with a reactor temperature from $200^{\circ} \mathrm{C}$ to $300{ }^{\circ} \mathrm{C}$ [28]. An equilibrium temperature approach of $3.6^{\circ} \mathrm{C}$ was considered to account for the deviations from equilibrium, with recycling of the unreacted gases, purge of $5 \%$ and preheating to $200^{\circ} \mathrm{C}$.

\subsection{Energy integration}

The use of external utilities, such as gas boilers and refrigeration cycles, should be minimised to decrease the fuel/electricity consumption and operating costs. This can be achieved by analysing the temperature levels and heat demands of each process, and promoting internal heat recovery. For example, heat can 
be recovered from the reactors in which exothermic reactions take place (methanation, water-gas-shift and methanol synthesis) or where gas cooling is required (partial condensation of the process gases). It can be used for steam production (gasification, reforming and electrolysis), gas preheating or $\mathrm{CO}_{2}$-removal by chemical absorption. An individual temperature approach was defined for each stream to account for the minimum heat transfer driving force within each heat exchanger. They were taken to $5{ }^{\circ} \mathrm{C}, 10^{\circ} \mathrm{C}$ and $20^{\circ} \mathrm{C}$ for condensing/evaporating, liquid and gaseous streams.

\section{Methods}

The present section builds on models developed in a previous paper by the authors [20]: the process and thermodynamic performances (inputs, outputs, efficiencies) of each type of plant are given in Appendix A. The process models developed in DNA and Aspen Plus were used to retrieve all the information such as temperatures, pressures, heating and power demands for further component sizing and economic analyses.

\subsection{Economic assessment}

This section presents the methods followed to perform the economic assessment of the different polygeneration concepts presented earlier, from the estimation of the capital costs to the calculation of the minimum selling price of bio-oil. The general assumptions are listed in Table 3 and are based on the hypotheses generally taken for biofuel production plants with pyrolysis (the interested reader is referred to the papers listed in Section 1).

Table 3: General parameters for the economic analysis

\begin{tabular}{ll}
\hline Base year & 2017 \\
Plant lifetime & 25 years \\
Plant availability & $90 \%$ \\
\hline
\end{tabular}

\subsubsection{Capital costs}

The module costing method of Turton et al.[37] was used for performing preliminary cost estimations. The grassroot costs $C_{\mathrm{GR}}$ represent the total investment costs, deduced from the bare module $\operatorname{costs} C_{\mathrm{bm}}$ and purchased equipment $\operatorname{costs} C_{\mathrm{pc}}$, and were calculated following these four steps:

- the purchased-equipment costs of each item $C_{\mathrm{PC}}$ were estimated by cost correlations (Equation 1) assuming atmospheric pressure conditions and carbon steel construction, using equipment-based factors $\left(k_{1}, k_{2}\right.$ and $\left.k_{3}\right)$ and a size parameter $(S$, which, for example, corresponds to the heat transfer area for heat exchangers and power demand for compressors):

$$
\log _{10} C_{\mathrm{PC}}=k_{1}+k_{2} \log _{10} S+k_{3}\left(\log _{10} S\right)^{2}
$$

- the bare module costs $C_{\mathrm{BM}}$ were obtained (Equation 2) adjusting the purchased-equipment costs with pressure $\left(f_{p}\right)$, material $\left(f_{m}\right)$ and equipment-based $\left(b_{1}, b_{2}\right)$ factors:

$$
C_{\mathrm{BM}}=C_{\mathrm{PC}}\left(b_{1}+b_{2} f_{m} f_{p}\right)
$$

- the bare module costs in baseline conditions (no need for special materials or to account for specific pressure operating conditions) were directly deduced from the equipment-based factors, which account for the direct and indirect costs (Equation 3):

$$
C_{\mathrm{BM}}^{0}=C_{\mathrm{PC}}\left(b_{1}+b_{2}\right)
$$


- the actualised bare module costs $C_{\mathrm{BM}}$ were computed (Equation 4 ), considering the inflation between the reference year of the cost data and the date of the estimate with the Marshall Swift Indexes:

$$
C_{\mathrm{BM}, 2017}=C_{\mathrm{BM}}\left(\frac{\mathrm{MSI}_{2017}}{\mathrm{MSI}_{\mathrm{ref}}}\right)
$$

- the grassroot costs $C_{\mathrm{GR}}$, i.e. the total investment costs when installing the equipment items on a new production site (Equation 5) were deduced from:

$$
C_{\mathrm{GR}}=\left(1+\alpha_{1}\right) \sum_{i} C_{\mathrm{BM}, i}+\alpha_{2} \sum_{i} C_{\mathrm{BM}, i}^{0}
$$

where the factor $\alpha_{1}(\simeq 0.38)$ accounts for the contingencies $(\simeq 0.35)$ and fees $(\simeq 0.03)$ and the factor $\alpha_{2}(\simeq 0.50)$ for the auxiliary facilities and site development.

However, correlations for all process components and sections may not be available in the handbooks of [37-39] and other empirical laws were used in these cases. In general, such cost estimates are not given for the desired component size and should be scaled following a power law (Equation 6), where $S_{\text {ref }}$ is the reference size and $\alpha$ the cost capacity exponent. This approach was applied for estimating the costs of the biomass feeding, hydropyrolysis and electrolysis sections (Table 4). The cost of a high-temperature char combustor that can provide heat through radiation and convection to the reformer could not be found in the literature, as this is a novel technology not widely developed and implemented. A conservative approach was applied in this work, and the installed costs of this technology were set equal to those of hydropyrolysis. The gasification cost was derived from cost correlations in the literature, to which were added the costs of an ash cyclone, a ceramic filter, a tar cracker and a heat exchanger.

$$
C_{\mathrm{BM}}=C_{\mathrm{BM}, \mathrm{ref}} \cdot\left(\frac{S}{S_{\mathrm{ref}}}\right)^{\alpha}
$$

The methanation and methanol synthesis reactors were assumed to be of the fluidised bed type, and the cost correlations found in the literature [37] are based on the reactor volume as a capacity factor. The diameter (Equation 7) and height (Equation 8) were calculated considering the operating conditions (temperature and pressure) and fluid properties (volume flowrate and velocity), using empirical laws adjusted to fit data from existing plants [27] and assuming a constant fluid velocity during scale-up (Table 5).

$$
\begin{gathered}
d=2 \sqrt{\frac{\dot{V}}{\pi u_{m}}} \\
h=h_{0} \dot{V}^{b}
\end{gathered}
$$

\subsubsection{Manufacturing costs}

The manufacturing costs were estimated following the method presented in Turton et al.[37] (Table 6). They are usually divided into the direct costs (raw materials, utilities) and indirect ones (maintenance, labor, insurance and taxes). The costs of the raw materials (e.g. biomass and catalysts) and utilities (e.g. electricity and cooling water) were set to the mid-2018 values (Table 7). The prices of the biomass feedstock, power, methanol and synthetic natural gas depend on the market conditions and plant locations. They are also impacted by political incentives, such as feed-in tariffs and subsidies for green fuels. The Danish stock market and tax conditions [43-45] were assumed. For a detailed description and explanation of the fuel and electricity costs, the reader is referred to the notes given in each table. The indirect charges were calculated based on assumptions presented in Turton et al.[37] and are listed in Table 6. There is no consensus on the values of the annual maintenance costs for biorefinery plants, which generally vary between $4 \%$ and $8 \%$ of the investment costs. This value depends on the plant size and components and was taken here to $6 \%$. 
Table 4: Reference cost data ${ }^{\mathrm{a}}$

\begin{tabular}{|c|c|c|c|c|c|}
\hline Equipment & $C_{\mathrm{BM}, \mathrm{ref}}^{\mathrm{b}}$ & $\alpha$ & $\mathrm{S}_{\mathrm{ref}}$ & Unit & Reference \\
\hline Conveyers & 1.36 & 0.8 & 33.5 & wet tonne/h & {$[40]$} \\
\hline Grinding & 1.58 & 0.6 & 33.5 & wet tonne/h & {$[40]$} \\
\hline Storage & 3.82 & 0.65 & 33.5 & wet tonne/h & {$[40]$} \\
\hline Iron removal ${ }^{\mathrm{c}}$ & 1.42 & 0.7 & 33.5 & wet tonne/h & {$[40]$} \\
\hline Feeding system ${ }^{\mathrm{d}}$ & 1.58 & 0.7 & 33.5 & wet tonne/h & {$[40]$} \\
\hline Hydropyrolysis & 14.01 & 0.7 & 2000 & tonne/day & [18] \\
\hline PSA units ${ }^{\mathrm{e}}$ & 0.51 & 0.66 & 0.06 & $\mathrm{~m}^{3} / \mathrm{s}($ total $)$ & {$[37]$} \\
\hline Reformer & 121 & 0.6 & 100 & $\mathrm{~m}^{3} / \mathrm{s}(\mathrm{NTP})$ & {$[40]$} \\
\hline WGS unit & 37.4 & 0.65 & 8819 & $\mathrm{kmol} / \mathrm{h}\left(\mathrm{CO}+\mathrm{H}_{2}\right)$ & {$[40]$} \\
\hline $\mathrm{SOEC}^{\mathrm{f}}$ & 0.20 & 0.9 & 250 & $\mathrm{MW}$ & [41] \\
\hline $\mathrm{AEC}^{\mathrm{g}}$ & 0.50 & 0.9 & 250 & MW & [41] \\
\hline Gasifier & 9.05 & 0.7 & 41.7 & tonne/hour (char) & {$[42]$} \\
\hline Ash cyclone & 1.3 & 0.7 & 68.7 & $\mathrm{~m}^{3} / \mathrm{s}$ (gas feed) & {$[42]$} \\
\hline Ceramic filter & 2.3 & 0.65 & 12.1 & $\mathrm{~m}^{3} / \mathrm{s}$ (gas feed) & [40] \\
\hline Tar cracker & 1.04 & 0.7 & 41.7 & $\mathrm{~m}^{3} / \mathrm{s}$ (gas feed) & {$[42]$} \\
\hline
\end{tabular}

${ }^{\text {a }}$ Data was updated to the base year 2017, which corresponds to a CEPCI of 567.5

b Equipment costs are given in million $\$_{2017}$

c An iron removal system was considered in the biomass pretreatment process, which may not be relevant for all types of feedstock. The expected reduction of costs if not applicable is about $15 \%$.

$\mathrm{d}$ The cost correlation was taken from Hamelinck et al.[40] but the scale factor was changed from 1 to 0.7 to account for the scale effects

e Example of simplified cost data derived from the correlations of Turton et al.[37] for four vertical vessels in parallel, made in stainless steel, packed with an adsorbent of cost and density of $4.5 \$ / \mathrm{kg}$ and $800 \mathrm{~kg} / \mathrm{m}^{3}$

f Corresponds to the projected price of SOECs in 2050 if produced in industrial scale and design challenges are overcome [41]

${ }^{g}$ Corresponds to the projected price of AECs in 2050 if produced in industrial scale [41]

Table 5: Parameters for reactor sizing [27] (the sizing parameter $b$ is reconciled for these reactors and is equal to 0.188)

\begin{tabular}{lrr}
\hline Reactor & $u_{m}(\mathrm{~m} / \mathrm{s})$ & $h_{0}\left(\mathrm{~m}\left(\mathrm{~m}^{3} \cdot \mathrm{s}^{-1}\right)^{-0.188}\right)$ \\
\hline Methanation & 0.093 & 18 \\
MeOH synthesis & 0.317 & $\frac{h}{d}=1.62$ \\
\hline
\end{tabular}


Table 6: Manufacturing cost data - the feedstock and utility cost data are given in Table 7

\begin{tabular}{lllr}
\hline & Value & Unit & Reference \\
\hline Direct manufacturing costs $^{a}$ & & & \\
Catalyst & 14,000 & $\$ /$ tonne & {$[18]$} \\
Operating labour ${ }^{\mathrm{b}} C_{\mathrm{OL}}$ & $70,000 \cdot 4.5 \cdot N_{\mathrm{OL}}$ & $\$ /$ year & {$[37]$} \\
Direct supervisory and clerical labor & $0.18 C_{\mathrm{OL}}$ & $\$ /$ year & {$[37]$} \\
Maintenance and repairs & $0.06 C_{\mathrm{GR}}$ & $\$ /$ year & {$[37]$} \\
Laboratory charges & $0.15 C_{\mathrm{OL}}$ & $\$ /$ year & {$[37]$} \\
Patents & $0.03 C_{\mathrm{OM}}$ & $\$ /$ year & {$[37]$} \\
& & & \\
Fixed manufacturing costs & $0.032 C_{\mathrm{GR}}$ & $\$ /$ year & \\
Local taxes & $0.708 C_{\mathrm{OL}}+0.036 C_{\mathrm{GR}}$ & $\$ /$ year & {$[37]$} \\
Plant overhead & & & {$[37]$} \\
& & & \\
General manufacturing costs & & & \\
Administration & $0.177 C_{\mathrm{OL}}+0.009 C_{\mathrm{GR}}$ & $\$ /$ year & {$[37]$} \\
Distribution & $0.11 C_{\mathrm{OM}}$ & $\$ /$ year & {$[37]$} \\
Research and development & $0.05 C_{\mathrm{OM}}$ & $\$ /$ year & {$[37]$} \\
\hline
\end{tabular}

${ }^{a}$ Direct manufacturing costs such as feedstock and electricity costs are given in Table 7

b The operating labour costs were calculated from the cost correlation of Alkhayat and Gerrard for estimating the number of operators per shift, as presented in Turton et al.[37], and assuming 1095 operating shifts per year and an average yearly salary of $\$ 70,000$.

${ }^{\mathrm{c}}$ In the rest of the study, costs that are a function of the total operating costs are grouped under the heading 'General manufacturing costs and others'

Table 7: Energy cost data, given on a LHV basis

\begin{tabular}{lllr}
\hline & Value & Unit & Reference \\
\hline Biomass & 25.6 & \$/MWh & {$[28,46]$} \\
& 7.1 & \$/GJ & \\
Electricity & 30 & \$/MWh & {$[47]$} \\
& 8.3 & \$/GJ & \\
Green SNG & 52 & \$/MWh & {$[43,48]$} \\
& 14.4 & \$/GJ & \\
Hydrogen & 2.5 & \$/kg & {$[49,50]$} \\
& 20.8 & \$/GJ & \\
MeOH & 420 & \$/tonne & {$[44]$} \\
& 21.1 & \$/GJ & \\
Bio-char & 42 & \$/tonne & {$[18]$} \\
& 1.5 & \$/GJ & \\
Process steam & 18 & \$/tonne & {$[18]$} \\
& 9.7 & \$/GJ & \\
\hline
\end{tabular}

\subsubsection{Profitability analysis}

The total annual costs include the capital repayments and the manufacturing costs (raw materials, utilities, operation and maintenance). The annual capital repayment $\left(C_{\mathrm{ACR}}\right)$ is the money required to pay back the loan contracted to build the plant, and is a function of the anticipated plant lifetime $n$, inflation rate $i$, discount rate $d$, and installed capital costs (Equation 9). 


$$
C_{\mathrm{ACR}}=C_{\mathrm{GR}} \cdot \frac{r_{\mathrm{eff}}\left(1+r_{\mathrm{eff}}\right)^{n}}{\left(1+r_{\mathrm{eff}}\right)^{n}-1}
$$

where $r_{\text {eff }}$ is the effective discount rate (Equation 10), defined by the Fisher equation as:

$$
r_{\mathrm{eff}}=\frac{1+d}{1+i}-1
$$

The fuel production costs (Equation 11) were then derived from the annual costs (repayments and operation) and normalised based on the total energy outputs (bio-oil and by-products). The price inflation of equipment and raw materials were disregarded for simplicity, and the same assumptions were taken to ensure a consistent comparison between all polygeneration concepts.

$$
C_{\mathrm{FP}}=\frac{C_{\mathrm{ACR}}+C_{\mathrm{OM}}}{8760 \cdot 3600 \cdot 0.9 \cdot\left(\dot{m}_{\text {bio-oil }} \mathrm{LHV}_{\text {bio-oil }}+\dot{m}_{\mathrm{SNG}} \mathrm{LHV}_{\mathrm{SNG}}+\dot{m}_{\mathrm{H} 2} \mathrm{LHV}_{\mathrm{H} 2}+\dot{m}_{\mathrm{MeOH}} \mathrm{LHV}_{\mathrm{MeOH}}\right)}
$$

Finally, the minimum selling price of bio-oil was calculated by performing a discounted cash flow rate of return (DCFROR) analysis. It is defined as the price at which bio-oil should be sold to achieve a net present value (NPV) of 0 , considering all cash inflows and outflows from capital repayments, operation and maintenance, by-product revenues, income tax rates and tax reductions due to plant depreciation. The DCFROR analysis was carried out based on a $n$th plant assumption (Table 8). It means that similar plants were established successfully, and all risks and costs due to equipment oversizing and artificial inflations were disregarded.

Table 8: General parameters for the profitability analysis

\begin{tabular}{ll}
\hline Inflation rate [51] & $1 \%$ \\
Discount rate & $8 \%$ \\
Depreciation method [37] & Straight-line method \\
Maximum depreciation ratio & $6 \%$ \\
Salvage value & $0 \$$ \\
Corporate tax rate [52] & $22 \%$ \\
\hline
\end{tabular}

\subsection{Sensitivity analysis}

Several model parameters were assumed based on the current economic conditions. However, they are subjected to high variability over time, and their variations may have a significant impact on the profitability of the polygeneration plants. A sensitivity analysis was therefore performed to identify the most influential and less important parameters. The methods described in the literature can be divided into two groups: local - one-factor-at-a-time (OAT) and global - sampling-based variance decomposition [53]. Local methods are derivative-based and focus on the impact of small input perturbations on the model output. They are mostly applicable for linear models and are not suitable for models presenting discontinuities. On the contrary, global methods use sample sets to consider the whole variation range of inputs and fully explore the design space [54]. Three methods were used and compared to identify the sensitive factors. They are based on the parameters and ranges listed in Table 9. These ranges were not defined uniformly, but based on an individual assessment.

\subsubsection{Local analysis}

A local sensitivity analysis was performed, varying one factor at a time, while always keeping the other parameters equal to the values defined in the baseline scenario. This scenario considers the prices of the biomass and power given in Table 7, with the economic conditions described in Table 3 and Table 8. This approach does not allow for a full exploration of the design space, as there are no simultaneous variations of the input variables. 
Table 9: Sensitivity characterization

\begin{tabular}{|c|c|c|}
\hline Variable & Lower limit & Upper limit \\
\hline Yield factor (-) ${ }^{a}$ & $70 \%$ & $130 \%$ \\
\hline Biomass price $(\$ / \mathrm{MWh})$ b & 21.6 & 50.4 \\
\hline Catalyst cost $(\$ / \text { tonne })^{\mathrm{c}}$ & 5000 & 14,000 \\
\hline Electricity price $(\$ / \mathrm{MWh}) \mathrm{d}$ & 19 & 60 \\
\hline Tax level (-) e & $20 \%$ & $40 \%$ \\
\hline Bio-SNG price $(\$ / M W h)^{f}$ & 22 & 76 \\
\hline Hydrogen price $(\$ / \mathrm{kg})^{\mathrm{g}}$ & 2 & 3 \\
\hline $\mathrm{MeOH}$ price $(\$ /$ tonne $) \mathrm{h}$ & 200 & 640 \\
\hline Char credit (\$/tonne) ${ }^{\mathrm{i}}$ & 11 & 287 \\
\hline Grassroot factor $(-)^{j}$ & $70 \%$ & $130 \%$ \\
\hline $\mathrm{SOEC} \operatorname{cost}(\mathrm{M} \$ / \mathrm{MW})^{\mathrm{k}}$ & 0.2 & 1.5 \\
\hline $\mathrm{AEC}$ cost $(\mathrm{M} \$ / \mathrm{MW})^{1}$ & 0.35 & 0.7 \\
\hline Lifetime (years) & 5 & 40 \\
\hline Discount rate $(-)$ & $5 \%$ & $15 \%$ \\
\hline
\end{tabular}

a The bio-oil yield may vary from $20 \%$ to $30 \%$ (weight) depending on the biomass feedstock and catalysts.

$\mathrm{b}$ The biomass price depends on the type of feedstock and country, and will likely increase in the future $[28,46]$.

c The upper limit for the catalyst cost was set to the value chosen in Tan et al.[18], and it is expected that it decreases in the future with the development of novel formulations.

$\mathrm{d}$ The price of electricity to industrial consumers strongly differs from country to country in the European Union, going from 46.2 \$/MWh (Luxemburg) to 140.3\$/MWh (Cyprus) in EU countries in 2017, assuming an annual power consumption superior to 20,000 MWh [55]. However, in the present work, the projected levelized cost of electricity from wind turbines was assumed instead, using the estimates of Lazard Ltd.[47], as the objective is to assess the possible integration of renewable energy for producing chemical fuels (power-to-fuel).

e The income tax level depends on the country in which the plant is built and is generally assumed in the range of $20 \%$ (Danish financial environment) to 35-40\% (as assumed in several American studies from NREL [18]).

$\mathrm{f}$ The price of natural gas to large industrial consumers strongly differs from country to country in the European Union, going from $25 \$ / \mathrm{MWh}$ (Belgium) to $48 \$ / \mathrm{MWh}$ (Finland) in EU countries in 2015 [56]. Subsidies for promoting synthetic natural gas production depend on the EU country, but generally take place in the form of feed-in tariffs that may bring the SNG cost to up to $76 \$ / \mathrm{MWh}$ in Denmark $[43,48]$.

$\mathrm{g}$ The hydrogen price was taken as $2.5 \$ / \mathrm{kg}$, as an estimate of the values expected for hydrogen production from conventional steam reforming [50]. It corresponds as well to the value expected when applying the relationship between the natural gas and hydrogen production cost suggested by Penner[49] assuming a natural gas price of about 25 to $30 \$ / \mathrm{MWh}$.

h The methanol posted contract price varied from $200 \$ /$ ton to $640 \$ /$ ton in the period 2008-2018 [44].

i Char may be seen as a by-product for which financial benefits can be obtained, at a low rate of $11 \$ / \mathrm{kg}$ as suggested in some papers [18], or at a high rate of $287 \$ / \mathrm{kg}$, assuming it could be sold at least at the same price as biomass, on an energy basis. The value is corrected to account for the higher heating value of char compared to biomass.

$\mathrm{j}$ The deviation in the investment costs depends on the plant scale and selected cost correlations, but is generally assumed to be in a range of $\pm 30 \%$ in preliminary cost evaluations [37].

${ }^{\mathrm{k}}$ A specific investment cost for SOEC is difficult to estimate, as this depends on the size, the manufacturer, the production year and scale. The projections presented in the literature range from $0.2 \mathrm{M} \$$ to $3.50 \mathrm{M} \$$ per $\mathrm{MW}$ of electricity consumption, on a time horizon from 2020 to 2050 [41].

${ }^{1}$ As for SOECs, a specific cost for AECs is difficult to estimate, but the projections given in the literature range from $0.58 \mathrm{M} \$$ to $1.25 \mathrm{M} \$$ per $\mathrm{MW}$ of electricity consumption, on a time horizon from 2020 to 2050 [41]. 


\subsubsection{Morris screening}

Afterwards, the Morris method [57] was applied to ease a global sensitivity analysis, discretizing the model inputs, generating samples of parameter values using random OAT designs and calculating the minimum fuel selling price for each. This method consists of five consecutive steps, from the parameter sampling to the calculation of sensitivity measures. Firstly, a set of start values of the $k$ input parameters (e.g. natural gas price) is generated and the model outcome (e.g. minimum selling price) is calculated. Secondly, each input is varied while the others are kept constant, and this goes on until all the inputs are changed. Each input can only take values corresponding to a set of $p$ levels within its sensitivity range. Thirdly, these two steps are replicated $r$ times at other and random points in the design space, which leads to a number of $r(k+1)$ evaluations when applying the sampling method of Morris [57]. The changes in the model output $(y)$ due solely to changes in a particular input $(x)$ are named elementary effects $(E)$ and are calculated for the $j$-th variable and $i$-th evaluation (Equation 12).

$$
E_{j}^{(i)}=\frac{\partial y}{\partial x_{j}} \simeq \frac{y\left(x_{1}, x_{2}, x_{j}+\Delta, \ldots, x_{k}\right)-y(\mathbf{X})}{\Delta}
$$

The elementary effects are then scaled using the standard deviation of the model outputs $\sigma_{y_{i}}$ and factors $\sigma_{x_{j}}$ to obtain non-dimensional measures, denoted $S E_{j}^{(i)}$ (Equation 13).

$$
S E_{j}^{(i)}=E_{j}^{(i)} \frac{\sigma_{x_{j}}}{\sigma_{y_{i}}}
$$

In a final step, the approximate distribution of these local derivatives is studied to assess the model sensitivity, and two indicators are used to this purpose:

- the mean of the absolute values of the (standardised) elementary effects $\left(\mu^{*}\right)$ [58]. It is a measure of the influence of the $j$-th input on the model output (Equation 14). High sensitivity to a given $j$-th input is characterised by a large $\mu_{j}^{*}$.

$$
\mu_{j}^{*}=\frac{1}{r} \sum_{i=1}^{r}\left|S E_{j}^{(i)}\right|
$$

- the standard deviation of the (standardised) elementary effects $(\sigma)$. It is a measure of the non-linear effects of the $j$-th input on the model output or of its interactions with the remaining $k-1$ factors (Equation 15). Small $\sigma_{j}$ suggest linear relationships between the $j$-th input and the model output.

$$
\sigma_{j}=\sqrt{\frac{1}{r} \sum_{i=1}^{r}\left(S E_{j}^{(i)}-\frac{1}{r} \sum_{i=1}^{r} S E_{j}^{(i)}\right)^{2}}
$$

Parameters with low $\mu$ and low $\sigma$ (thresholds as suggested in Sin and Gernaey[53]) are deemed as noninfluential. In contrast to local methods, the Morris method allows to screen factors in models of large dimensionality, without any assumption on their behaviour, and has two degrees of freedom: the numbers of repetitions $r(\{4-15\})$ and of levels $p(\{4,6,8\})$. For each screening, both $r$ and $p$ were set to ensure that no false relationships between input parameters and model outputs were found (type I statistical errors) and that all important input parameters were properly identified (type II statistical errors). These values were at first set to those suggested in

citetSin2009 and increased until both types of errors were avoided. The sensitivity of the minimum selling price of bio-oil to both technical and economic parameters was investigated in details, the lower and upper bounds being selected based on current economic environments in the European Union (Table 9). Despite using OAT designs, this method can be regarded as global since it builds on the average of partial derivatives calculated over the entire input space. 


\subsubsection{Multivariate linear regression}

Finally, a multivariate linear regression analysis was performed, based on Monte-Carlo simulations described further in the paper, to analyse the relations between the parameters deemed uncertain and their impact on the final results. Such method aims at modelling the relationship between all input variables $(x)$ and the output $(y)$ by fitting a linear equation to the computed data (Equation 16). It can thus only be applied if the model can be linearised, which is a fair assumption if the coefficient of determination $\left(R^{2}\right)$ is above $0.7[59]$.

$$
y=b_{0}+\sum_{i=1}^{n} b_{i} x_{j}+\varepsilon
$$

where $b_{i}$ is the regression coefficient of the $i$ th parameter and $\varepsilon$ is the regression error. This relation can be rewritten as a function of the standardised regression coefficients (Equation 17), also named beta coefficients $\beta$. The input-output relations are usually assessed with these indicators which take a value in the interval $[-1,1]$.

$$
\frac{y-\mu_{y}}{\sigma_{y}}=\sum_{i=1}^{n} \beta_{i} \frac{x_{i}-\mu_{x_{i}}}{\sigma_{x_{i}}}
$$

They describe the magnitude of the influence of a given parameter, and whether it has a positive or negative effect (Equation 18). The sum of the squared beta coefficients is $R^{2}$, and the difference between $R^{2}$ and unity reflects the non-linear behaviour of the model and possible interaction effects between the input variables.

$$
\beta_{i}=b_{i} \frac{\sigma_{x_{i}}}{\sigma_{y}}
$$

Linear regression analyses based on Monte-Carlo simulations are more accurate than local sensitivity approaches, while Morris screening assessments are more resilient to type II statistical errors.

\subsection{Uncertainty assessment}

Sensitivity analyses can be used to analyse how variations of the electricity price will affect the operating costs of a biorefinery. However, unlike uncertainty analyses, they cannot be used to assess all the possible model outcomes and the occurrence of each. For instance, sensitivity analyses cannot be used to estimate how likely the bio-oil produced in a thermochemical biorefinery will be cheaper than conventional gasoline. In practice, there are uncertainties related to discrepancies between simulation models and real systems, approximations in numerical models, and rough estimates and assumptions, and a probability distribution should thus be assumed for each variable. Their values should be changed simultaneously when carrying out model simulations, and the capital and production costs should be recalculated at each iteration.

A Monte-Carlo procedure was applied to find all the possible model outputs and their corresponding probabilities [60]. Firstly, the input parameters considered as uncertain (e.g. the cost of electricity) are determined, and the uncertainty range and distribution (e.g. normal, uniform, beta) of these $k$ variables are defined. Secondly, $N$ samples for these probability distributions are generated randomly in the whole input space, which has then a dimension of $N$-by- $k$. Thirdly, these samples are propagated through the model to calculate the desired outputs for each evaluation, and the final results are aggregated as density functions. The beta-distributions are presented graphically in Appendix C.

The uncertainty in the minimum selling price of bio-oil was assessed in the present work, considering the same input parameters as for the sensitivity analyses. Their range and distribution (Table 10) were estimated based on reference textbooks (e.g. grassroot cost correlations), historical data (e.g. natural gas price), and estimates from companies and universities (e.g. installation costs of electrolysis cells). The random parameter values were generated by conducting a Latin Hypercube Sampling (LHS) [61], which is a method more efficient than random sampling tools for producing stable results and avoiding monotonicity issues [62]. The approach of the present analysis is described in further details in the work of Sin et al.[59]. 
Table 10: Uncertainty characterization

\begin{tabular}{|c|c|c|c|c|c|}
\hline Variable & Distribution & Parameter $1^{\mathrm{a}}$ & Parameter $2^{\mathrm{b}}$ & Parameter $3^{\mathrm{c}}$ & Parameter $4^{\mathrm{d}}$ \\
\hline Bio-oil yield (-) ${ }^{\text {e }}$ & Uniform & $70 \%$ & $130 \%$ & & \\
\hline Biomass price $(\$ / M W h)^{f}$ & Normal & 25.6 & 6.6 & & \\
\hline Catalyst cost (\$/tonne $)^{\mathrm{g}}$ & Normal & 14,000 & 2000 & & \\
\hline Electricity price $(\$ / \mathrm{MWh})$ & ${ }^{\mathrm{h}}$ Beta & 1.8 & 4 & 19 & 60 \\
\hline Tax level (-) i & Uniform & $20 \%$ & $40 \%$ & & \\
\hline Bio-SNG price $(\$ / M W h)^{j}$ & Uniform & 44 & 76 & & \\
\hline Hydrogen price $(\$ / \mathrm{kg})^{\mathrm{k}}$ & Uniform & 2 & 3 & & \\
\hline $\mathrm{MeOH}$ price $(\$ / \text { ton })^{l}$ & Uniform & 200 & 640 & & \\
\hline Char credit $(\$ / \text { ton })^{\mathrm{m}}$ & Uniform & 42 & 287 & & \\
\hline Grassroot costs (-) & Uniform & $70 \%$ & $130 \%$ & & \\
\hline SOEC cost $(M \$ / M W)^{n}$ & Beta & 2 & 4 & 0.2 & 1.5 \\
\hline $\mathrm{AEC}$ cost $(\mathrm{M} \$ / \mathrm{MW})$ & Uniform & 0.35 & 0.7 & & \\
\hline Lifetime (years) ${ }^{\circ}$ & Beta & 5.8 & 5 & 5 & 40 \\
\hline Discount rate (-) & Normal & 0.1 & 0.02 & & \\
\hline Availability (hours) $\mathrm{p}$ & Beta & 3.9 & 1.2 & 438 & 8760 \\
\hline
\end{tabular}

${ }^{\mathrm{a}}$ Uniform: lower limit, Normal: mean value, Beta: shape parameter $a$

${ }^{\mathrm{b}}$ Uniform: upper limit, Normal: standard deviation, Beta: shape parameter $b$

${ }^{c}$ Beta: lower limit

${ }^{\mathrm{d}}$ Beta: upper limit

e The yields of bio-oil and (by-)products are assumed to vary independently by $\pm 30 \%$.

f The biomass price depends on the type of feedstock and country and is expected to increase in the future. Its distribution was assumed normal for simplicity, with a standard deviation similar to the values found in uncertainty analyses presented in the literature [28].

g The mean catalyst price was taken equal to the value assumed in the $\mathrm{IH}^{2}$ report but may decrease with the development of new catalysts.

h The parameters $a$ and $b$ of this beta distribution were derived based on the projections of levelized cost of electricity for wind power in the future $[47,63]$. The mean value of this distribution is about $\$ 32$ per MWh. An example of sample is presented in Appendix C.

i The corporate tax rate in Denmark was $22 \%$ at the beginning of 2018 , but its value differs significantly with the country under study. The values assumed in the literature may be between 30 and $40 \%$ if the United States were taken as the baseline case.

$\mathrm{j}$ The distribution parameters correspond to the expected price of bio-SNG in Denmark.

${ }^{\mathrm{k}}$ The distribution parameters correspond to the selling price of hydrogen from reforming of natural gas.

1 The distribution parameters were derived to reproduce the posted contract prices of $\mathrm{MeOH}$ in Europe in the last 10 years (2008-2017). In practice, the prices may be higher as the MeOH produced from biomass may be sold at a higher value.

$\mathrm{m}$ The char credit depends on the market conditions for such by-products of hydropyrolysis - however, as it is a fuel with high heating value, it was assumed that its maximum sales value was in the same order as of the biomass price.

${ }^{n}$ The parameters $a$ and $b$ of this beta distribution were derived to reproduce the projected prices for the years 2030-2050, considering the estimates of several works in the field [64-66], and with the uncertainty range given in the energy technology catalogue of Energinet[41]. The mean value of this distribution is about $\$ 700$ per $\mathrm{kW}$, which corresponds to a central estimate of the SOEC investments costs in 2030-2040. An example of sample is presented in Appendix C.

o The parameters $a$ and $b$ of this beta distribution were derived from Tock et al.[28], and the mean value of this distribution is about 25.5 years. An example of sample is presented in Appendix C.

$\mathrm{p}$ The parameters $a$ and $b$ of this beta distribution were derived from Tock et al.[28], and the mean value of this distribution is about 7000 hours per year. An example of sample is presented in Appendix C. 


\section{Results}

The results from the economic, sensitivity and uncertainty analyses of the polygeneration systems based on catalytic hydropyrolysis are presented and commented in the following section. They can serve as a baseline for future comparison between biomass-to-liquid fuel concepts based on hydropyrolysis. It is not the pretension of the authors to give exact estimates for the investment, operating or production costs, as those may change heavily depending on the initial assumptions. The system sizing has a direct impact on its economic performance because of the 'economies of scale' effect and lower utility prices for large plants. All systems were sized on a 2000 tonnes per day biomass input (dry) for ease of comparison with the scientific literature on this topic. This corresponds to a plant capacity of about $400 \mathrm{MW}$ of biomass (LHV). The influence of different alternatives for char valorisation, reformer heating, $\mathrm{CO}_{2}$-separation and $\mathrm{H}_{2}$-production on the plant profitability was analysed.

\subsection{Economic analysis}

\subsubsection{Capital costs}

A detailed breakdown of the total capital costs (Figure 2) shows that plants with electrolysis, whether processing steam or liquid water, are more expensive than those with reforming furnaces (up to $\$ 620$ million against down to $\$ 180$ million). Electrolysis systems are, at present, not produced in industrial scale but are still expected to represent a big share of the capital costs when reaching technological maturity. The selection of alkaline or solid oxide electrolysis cells depends on the actual year of construction and on the projected prices for these technologies. At present, AECs are less expensive because of their maturity and relatively high durability (technical lifetime of about 25 years). However, SOECs may become cheaper within the next 30 years if produced in large batches and with high capacity levels [41]. Steam reforming units are used worldwide for commercial hydrogen production. They are, though, still expensive components because of the need for catalyst tubes and materials suitable to high-temperature operation. The capital costs of the heat exchangers were lumped into each process category when they were internal and into the 'HEX network' class if they were operating over different sections of the polygeneration plants.

The generation of SNG only adds very little to the plant capital costs, because light hydrocarbons are generated in the hydropyrolysis step, and limited processing is thus required to reach the desired gas composition. The production of $\mathrm{H}_{2}$ or $\mathrm{MeOH}$ results in greater capital costs because of the bigger size of the reforming unit, and of the high-pressure ( $\geq 90$ bar) processing steps for $\mathrm{MeOH}$ synthesis.

\subsubsection{Fuel production costs}

The production costs consist of the sum of the annualised capital costs, fixed and general manufacturing expenses, biomass and utility expenditures. They are expressed as the cost per total fuel output (bio-oil, $\mathrm{H}_{2}$, SNG, MeOH). A direct comparison of production costs between the twelve plants should therefore be done with care, as it then assumes that all fuel outputs are equally valuable. The total production costs range from $\$ 17$ to $\$ 24$ per GJ, and they are the highest for plants with electrolysis units (Figure 3). If the three cases considering SOECs are compared, it is clear that a minimum cost is achieved when SNG is co-produced, and a maximum if methanol is co-generated, because $\mathrm{MeOH}$ systems are characterized by both high investment (compressor, reformers and purification systems) and utility (power) expenses.

Each biomass-to-fuel plant is characterized by a different cost formation structure. The biomass cost is the major cost factor for most plants, whether with steam reforming or with steam electrolysis, followed by the electricity cost. The opposite trend is found for the plants with alkaline electrolysis, with the electricity costs being the major cost factor followed by the biomass expenditure. The investment costs represent from $11 \%$ to $16 \%$ of the total fuel production costs, even in cases with SOEC and AEC units, while fixed, general and other manufacturing costs account together for $25 \%$ to $30 \%$.

Physical absorption processes lead to smaller production costs than chemical absorption ones. The slightly higher capital costs of physical absorption units are compensated by the reduction in electricity costs if the heat required in chemical absorption systems is generated through an electric heater, as the power demand is much greater in the latter case. 


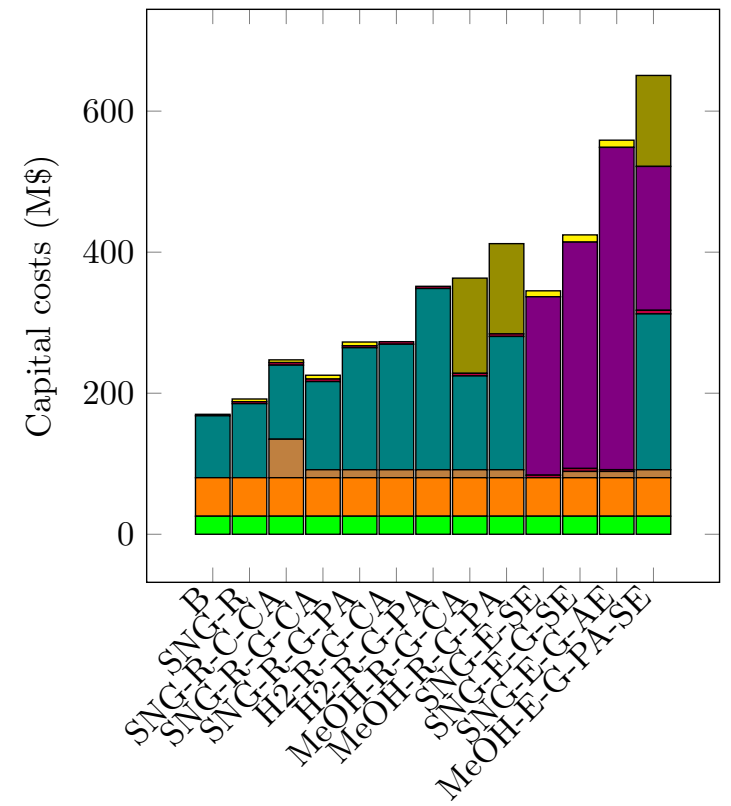

(a) Absolute values

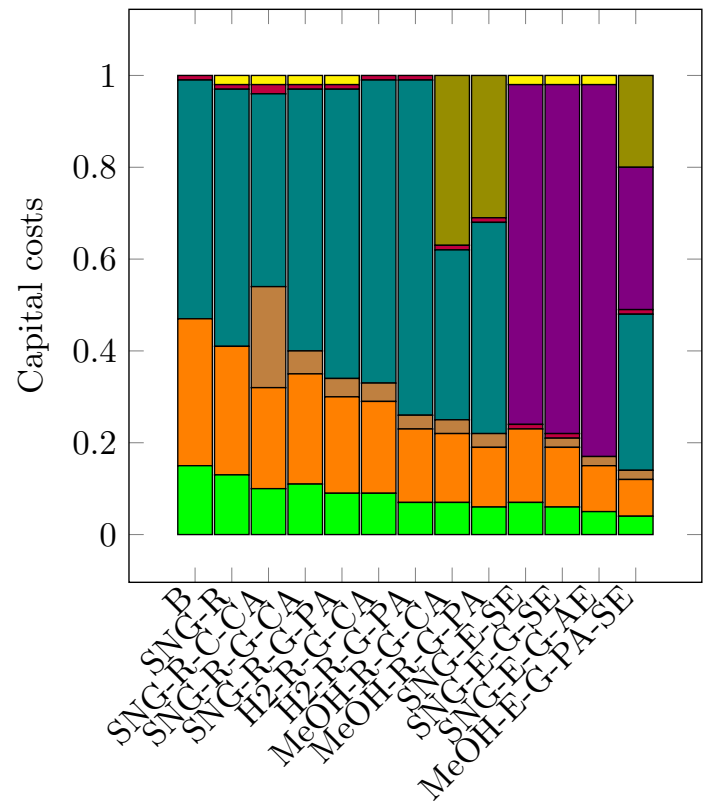

(b) Relative values

$\square$ Feed handling $\square$ Hydropyrolysis

Heat exchanger network

SOEC/AEC Char conversion $\mathrm{H}_{2}$ plant SNG synthesis $\mathrm{MeOH}$ synthesis

Figure 2: Capital costs of the polygeneration plants

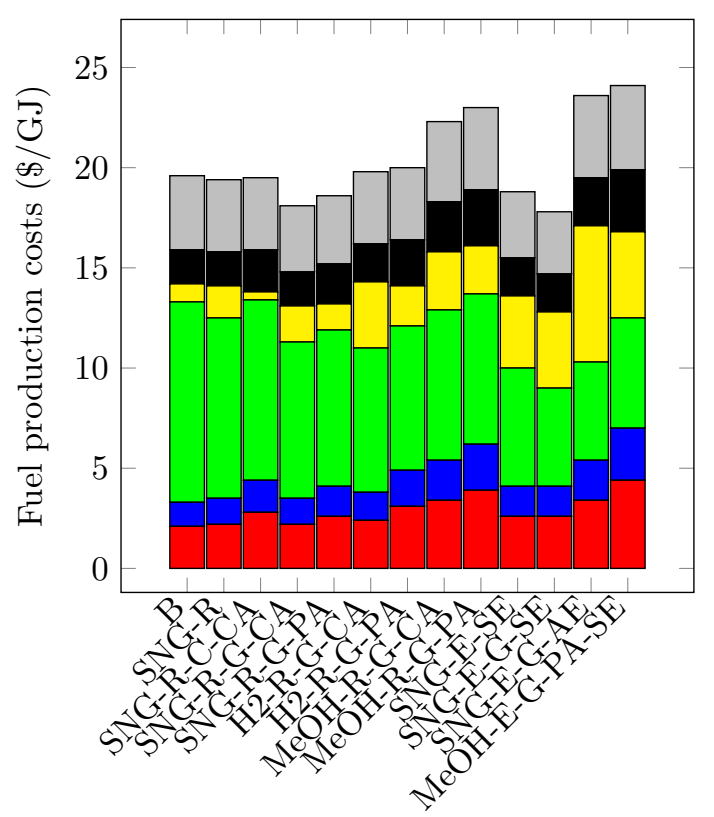

(a) Absolute values

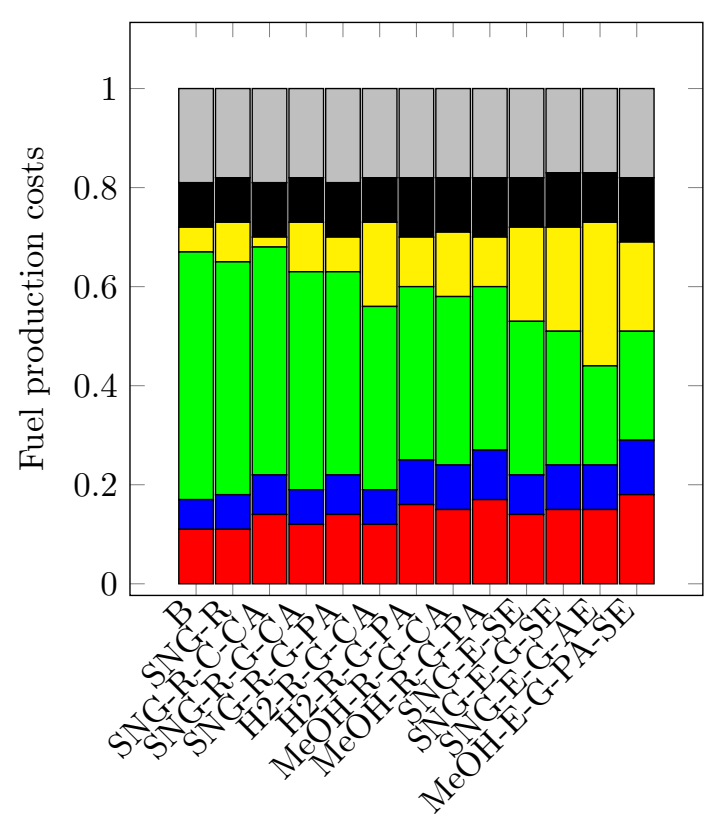

(b) Relative values

$\square$ Investment $\square$ Maintenance $\square$ Biomass

Electricity $\square$ Fixed manufacturing $\square$ General manufacturing and others

Figure 3: Fuel production costs of the polygeneration plants 
A local heat market can offer cost reductions in systems where excess heat is available, such as those with physical absorption and reforming units ('SNG-R-G-PA' and 'MeOH-R-G-PA'), or with alkaline electrolysis ('SNG-E-G-AE'). They are characterised by excess amounts of heat (from $4 \%$ to $20 \%$ of the biomass heating value) at about $250{ }^{\circ} \mathrm{C}$, which could be used for the production of high-pressure (25 bar) steam for process heating purposes. Similarly, financial credits may be obtained through sales of char for plants where it is not used for sustaining the reformer heating demand or for increasing the by-product yield. Char is characterised by a high carbon content and a heating value above $25 \mathrm{MJ} / \mathrm{kg}$ (LHV basis).

\subsubsection{Minimum fuel selling price}

The minimum fuel selling price (MFSP) was calculated for each polygeneration concept (Figure 4), using pre-fixed market values for the by-products and assuming that the net present value (NPV) has a value of 0 at the end of the plant lifetime. In practice, this implies that the real selling price should be set higher than the MFSP to ensure smaller payback periods and reduce the impact of the uncertainties associated with the future market prices and economic conditions. For example, in the case of the standard hydropyrolysis system, a discounted payback time (NPV of 0 ) of 5 years corresponds to a MFSP $10 \%$ higher than the value of the MFSP calculated for 25 years. This moderate increase can be justified by the small contribution of the total grassroot expenses in the production costs, implying that the revenues from the sales of bio-oil mostly compensate for the biomass and power costs. The MFSP for the baseline case was found to be around $\$ 2.6$ per gallon.

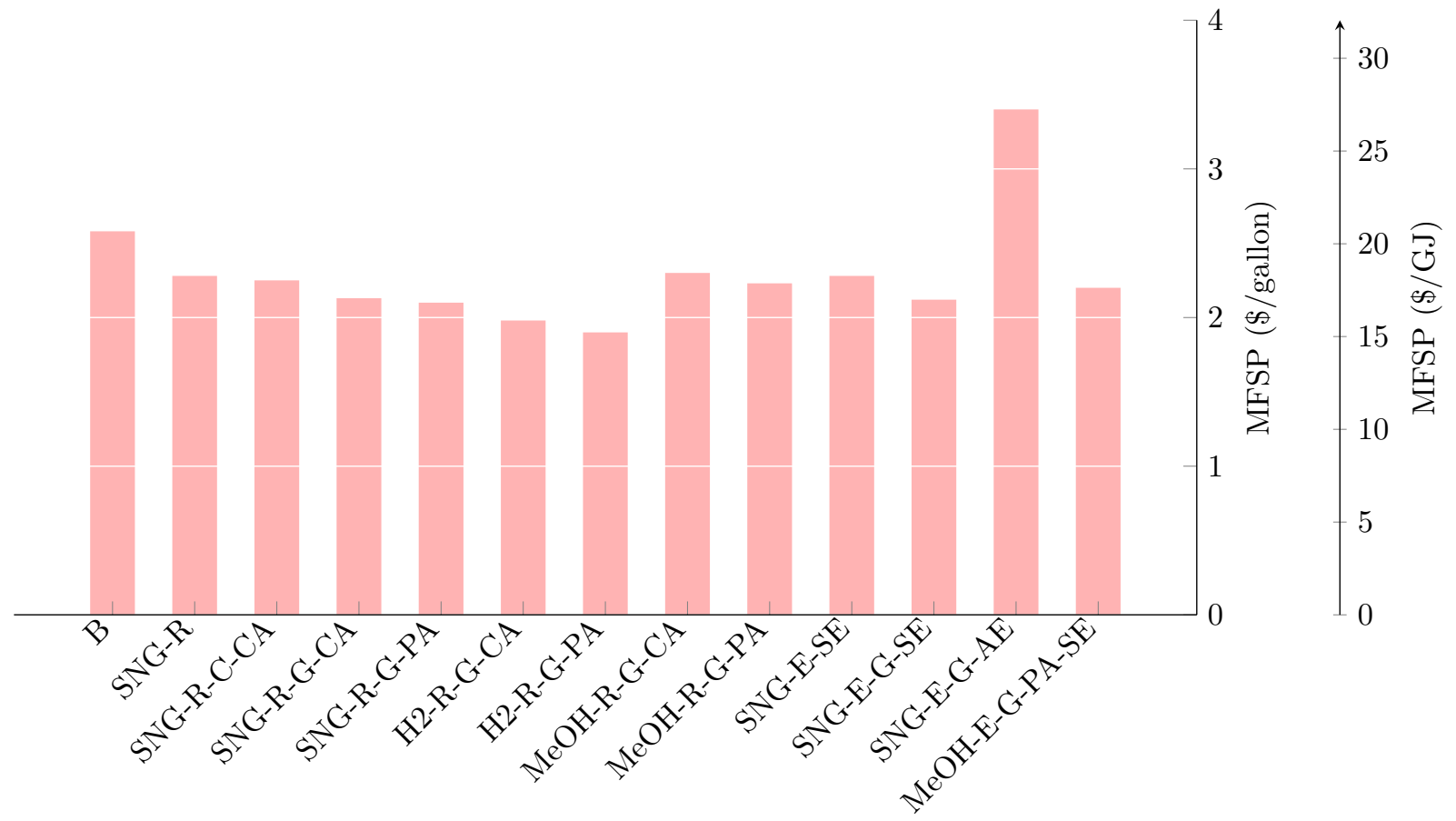

Figure 4: Minimum fuel selling price for each polygeneration concept

The co-generation of SNG, $\mathrm{H}_{2}$ and MeOH results, in most cases, in lower MFSPs than in the baseline case, with a reduction from $1 \%$ to $30 \%$. The biggest reduction $(\simeq 30 \%)$ is achieved by the plant design with $\mathrm{H}_{2}$ production and $\mathrm{CO}_{2}$-removal by physical absorption ('H2-R-G-PA'). The low MFSP of the 'H2-R-G-PA' layout results from the moderate electricity demand (only $23 \%$ of the biomass LHV) and the high revenues associated with $\mathrm{H}_{2}$-production, as hydrogen has a higher market value than SNG on an energy basis.

Plants with electrolysis may achieve lower MFSPs than conventional hydropyrolysis systems, since the increase in the investment and power costs is slightly outweighed by the additional revenues with the by- 
product sales. However, this builds on the hypothesis that SOECs are installed at a specific cost of about $200 \$ / \mathrm{kW}$, with a stack lifetime of 10 years, and a base electricity cost of $\$ 30$ per MWh. Such figures may only be achieved in the long term (2050 horizon) with full technological development, since the expected price of SOECs in the next decade is in the range 1200-2500 $\$ / \mathrm{kW}$ [41]. Plants with AECs are likely less profitable than those with SOECs, since the power demand is higher by 33 to $50 \%$, depending on the operating conditions and level of heat integration.

Selling char results, at best, in a reduction of 2 to $3 \%$ of the MFSPs (with a conservative estimate of $\$ 42$ per ton), while the generation of process steam leads to a reduction of 4 to $6 \%$ (with an estimate of $\$ 18$ per GJ). Selling char instead of burning or gasifying is not an attractive option in the current economic conditions, as $\mathrm{SNG}, \mathrm{H}_{2}$ and $\mathrm{MeOH}$ have a much higher value per energy content, and this is illustrated by the lower MFSPs of the 'SNG-R-C' and 'SNG-R-G' layouts than of the 'SNG-R' configuration (up to $15 \%$ reduction).

\subsection{Sensitivity analysis}

\subsubsection{Local approach}

Local sensitivity analyses were conducted, analysing the effects of variations in process and economic parameters on the minimum selling price of bio-oil. At the opposite of other studies, these analyses were not carried out by changing each parameter one-at-a-time by a $\pm 30 \%$ of its baseline value. The ranges of variations were selected based on reasonable estimate ranges deduced, among other sources, from historical price data. Two examples of such analyses are presented graphically in Figure 5 and Figure 6 . Unlike conventional hydropyrolysis systems, in which only one fuel (bio-oil) is produced, polygeneration systems produce either $\mathrm{SNG}, \mathrm{H}_{2}$ or $\mathrm{MeOH}$ in addition. Variations of the market value of $\mathrm{SNG}$ and $\mathrm{MeOH}$ have a higher impact on the profitability of systems with electrolysis ('SNG-E' and 'MeOH-E' concepts) than for systems with reforming ('SNG-R' and 'MeOH-R'), since the production of these two fuels is more than doubled (59 MW instead of 18-31 MW per $100 \mathrm{MW}$ of biomass for SNG plants, and $68 \mathrm{MW}$ instead of $33 \mathrm{MW}$ per $100 \mathrm{MW}$ of biomass for $\mathrm{MeOH}$ systems).

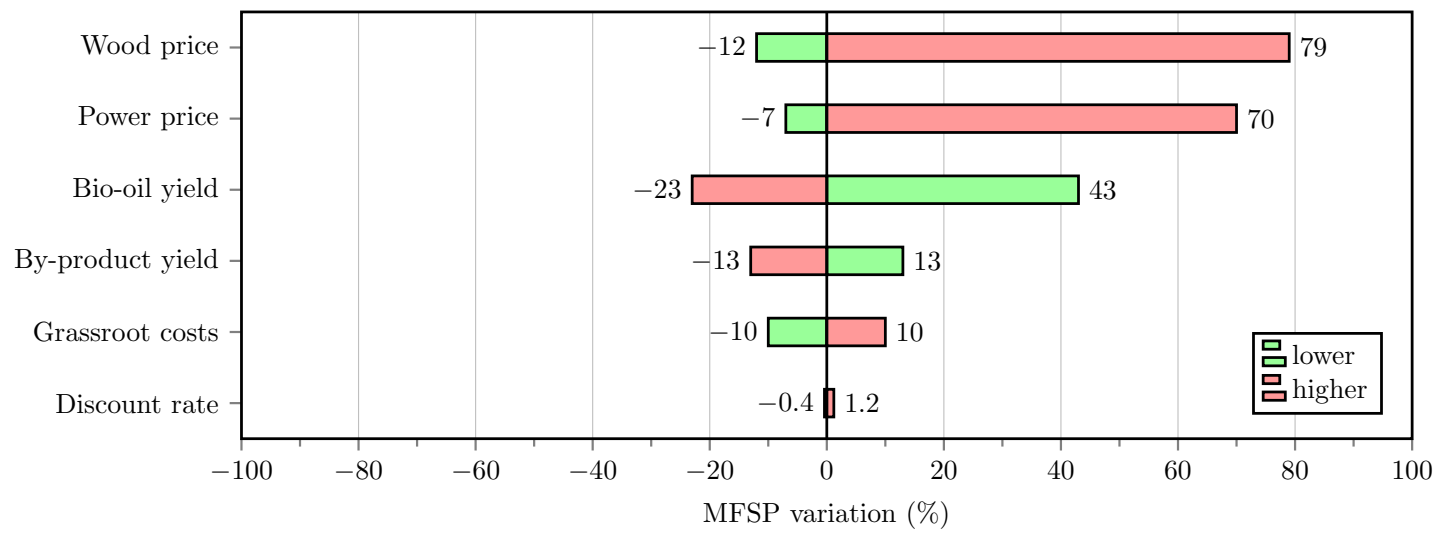

Figure 5: Local sensitivity analysis of the polygeneration concept 'SNG-R'

In addition, the deviations from the original value of the MFSP are usually not uniform even when an input parameter (e.g. grassroot costs) is varied uniformly by $\pm 30 \%$. For example, in the 'SNG-R' case, a higher fuel yield by $30 \%$ results in a reduction of $23 \%$ of the MFSP, whilst a lower fuel yield by $30 \%$ leads to an increase of $43 \%$. In general, for most parameters, the MFSP tends to increase rather than to decrease, which implies that a poorer process performance or less favourable economic environment will have a stronger impact on the plant profitability than technological improvements or higher by-product credits.

The most influential parameters are the biomass cost, electricity price (Figure 7), bio-oil yield and capital costs. For systems with steam reforming, the feedstock cost is the most sensitive factor (up to $100 \%$ above the MFSP calculated for the baseline case, of about $\$ 2.6$ per gallon), followed by the electricity price, while 


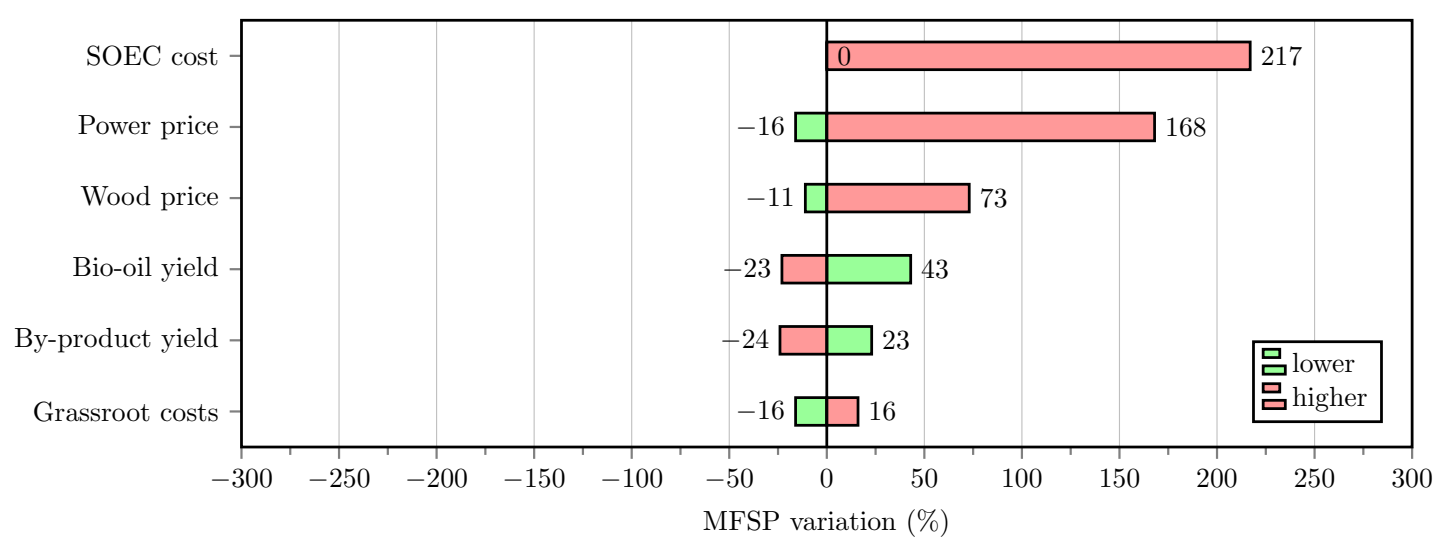

Figure 6: Local sensitivity analysis of the polygeneration concept 'SNG-E-G-SE'

the opposite ranking is found for systems with electrolysis. These two costs can differ significantly with the plant location and exceed the conventional $\pm 30 \%$ range selected in most articles. This is visible, for example, with the large gap in power prices between EU countries such as France and Germany. Low electricity prices are found in Nordic countries, making polygeneration concepts with electrolysis more competitive, with breaking-point values of $\$ 29-32$ per MWh of electricity. For example, methanol can be produced at a lower cost with electrolysis ('MeOH-E-G-PA-SE') than with reforming ('MeOH-R-G-PA') when the electricity price is lower than $\$ 32$ per MWh (Figure 7). Low spot electricity prices can be found in Nordic countries because of 'cheap' hydropower and subsidized wind power. However, in a time frame of 10 to 30 years, the levelized cost of electricity from unsubsidized wind power might decrease down to $\$ 20-30$ per MWh. A recent tender in Denmark achieved a record low subsidy for land wind (165 MW) and solar $(104 \mathrm{MW})$ of 3 euros $(\simeq \$ 3.4)$ per MWh [67].

The fuel output has also a great effect on the MFSP (up to $60 \%$ above the base value), which illustrates the need for developing more efficient hydropyrolysis systems with novel catalyst formulations. It is usually chosen to vary in a range of $\pm 10 \%$ to $\pm 30 \%$ in the literature. It is likely closer to the upper bound at present, since the hydropyrolysis systems investigated in this work are still novel.

Variations of the total grassroot costs have a significant impact as well (up to $30 \%$ above the base value), which suggests that a further reduction of the reforming and electrolysis costs, if possible, is essential. A sensitivity range of $\pm 30 \%$ is commonly chosen in the literature on BtL plants [18,23,37], and it is challenging to achieve higher accuracy of the capital cost estimates for such plants, which are not commercially available. Parameters such as the catalyst cost, char credit value and discount rate have a moderate to negligible (less than $10 \%$ above the base value) importance.

In a further step, the sales price of bio-oil was set constant, equal to the MFSP found in the baseline case. The electricity price was varied to find the minimum sales price at which the by-product $\left(\mathrm{SNG}, \mathrm{H}_{2}\right.$ or $\mathrm{MeOH}$ ) should be sold to ensure a NPV of 0 over the plant lifetime (Figure B.12). Low electricity prices result in lower minimum selling prices for the by-products, and the sensitivity analysis suggests that SNG can be sold at lower prices than $\mathrm{H}_{2}$ and $\mathrm{MeOH}$, which corresponds to the current economic situation.

Finally, the electricity price was kept constant, and the relation between the sales price of the bio-oil and of the by-products was derived (Figure B.13). For example, if the bio-oil can be sold at a price of $\$ 20$ per GJ, SNG should be sold at a price of at least $\$ 8.3$ per GJ to ensure that the 'SNG-R-G-PA' concept is profitable. In comparison, $\mathrm{MeOH}$ should be sold at a price of at least $\$ 18$ per GJ to ensure that the 'MeOH-R-G-PA' concept is economically acceptable.

\subsubsection{Morris screening}

A global sensitivity analysis was performed using Morris screening methods to identify the sensitive cost factors, and their ranking was based on the absolute mean of the distribution of the standard elementary effects $\mu^{*}$ (Figure 8$)$. At the opposite of a local sensitivity approach, more than one parameter may take a 


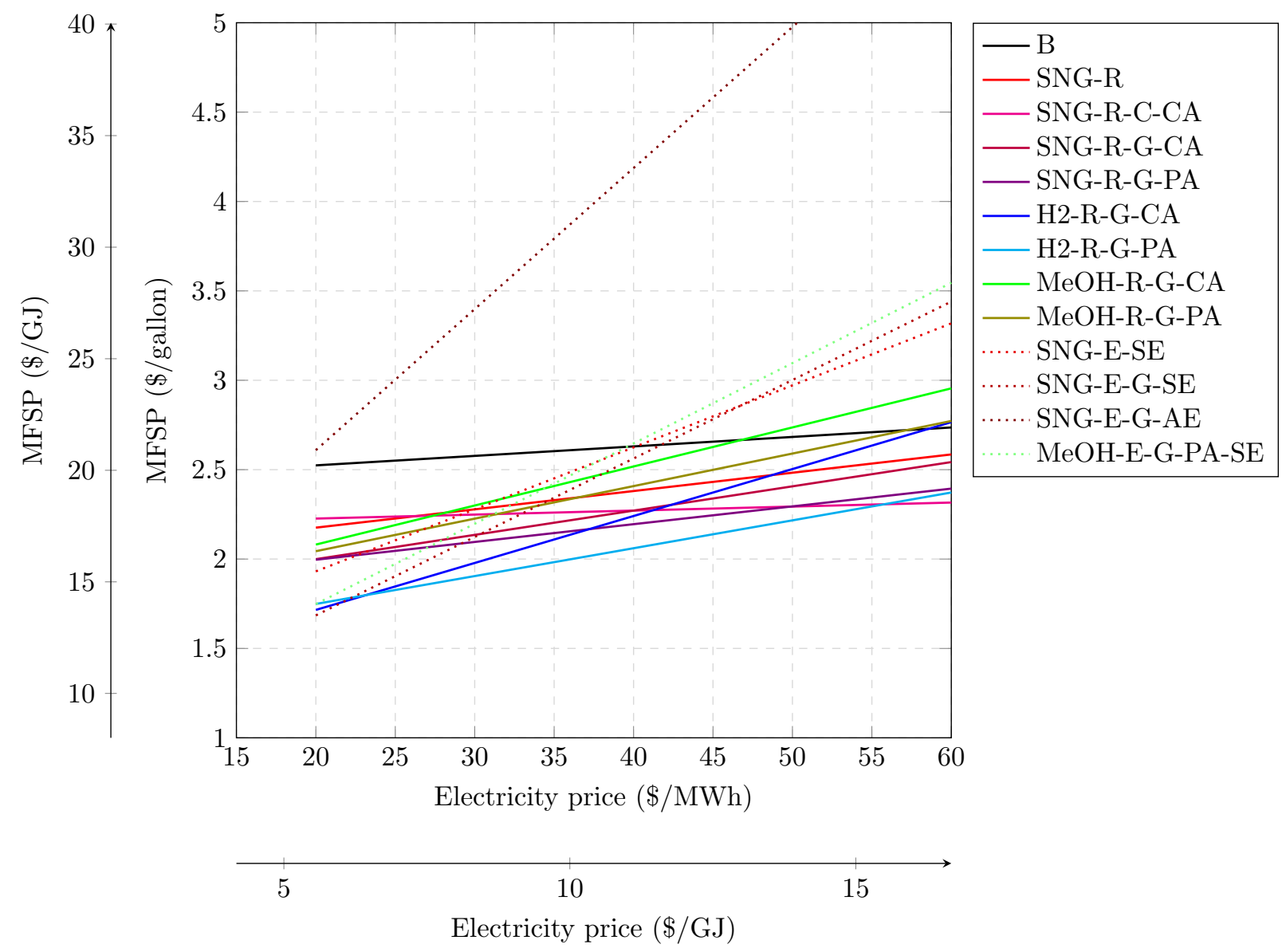

Figure 7: Local sensitivity analysis of all concepts with variations of the electricity price 
value different from its base one. This allows for exploring the entire input space and gives more information on how the profitability of the studied polygeneration plants is affected in situations where several prices (e.g. biomass, power, heat...) change simultaneously.

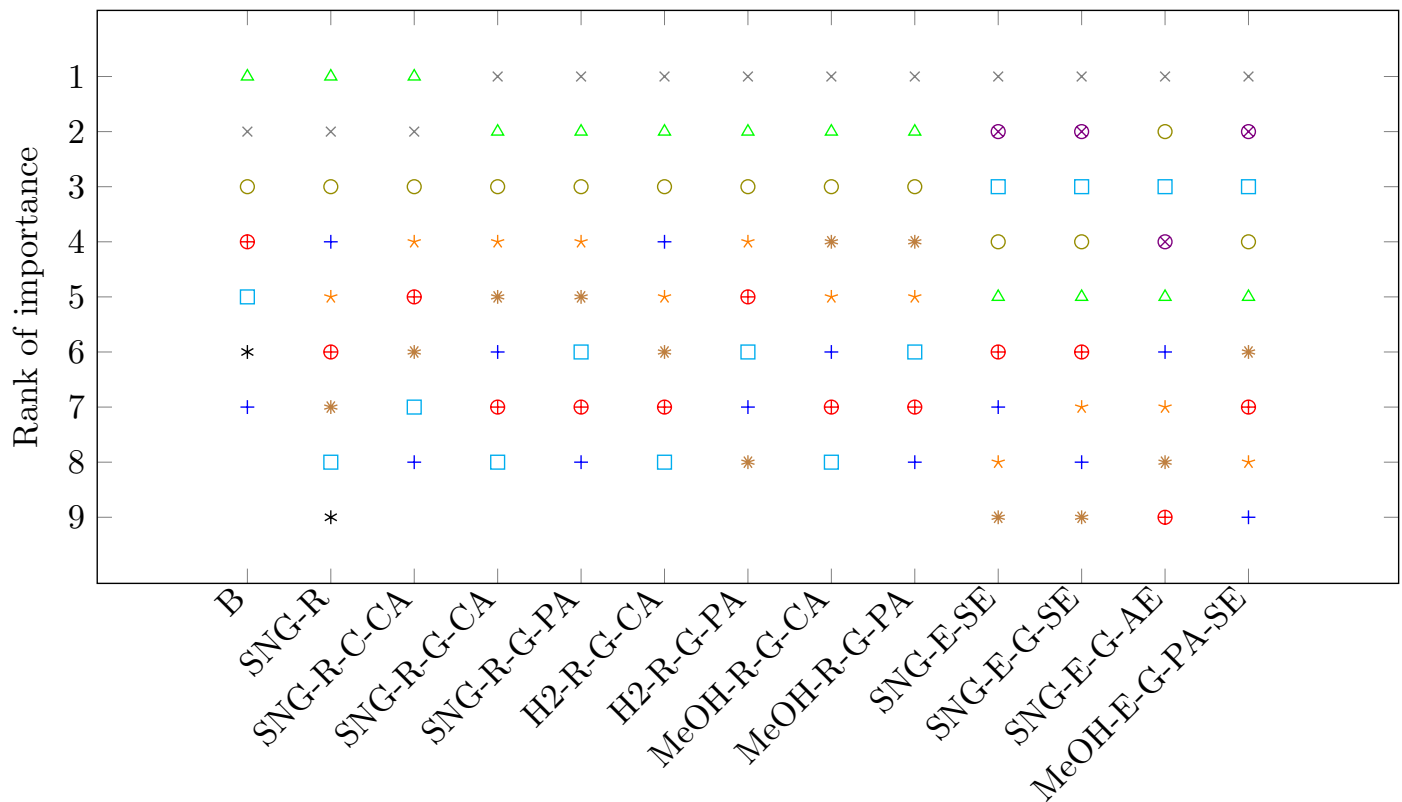

○ Bio-oil yield $\triangle$ Wood price $\times$ Plant availability + Electricity cost $*$ Char credit

$\star$ By-product yield * By-product price $\oplus$ Grassroot costs $\otimes$ Electrolysis costs $\square$ Lifetime

Figure 8: Sensitive parameters for each polygeneration layout, ranked based on their $\mu^{*}$ coefficients through Morris screening. Only parameters that are deemed influential are shown.

The number of operating hours per year (plant availability) and plant lifetime are two essential factors, ranking first to fourth in all cases. Few studies on biomass-to-fuel plants actually analysed the sensitivity to these parameters, and fixed values were generally assumed instead (e.g. $96 \%$ availability and 30 years plant life in Tan et al.[18]). Excluding these two, parameters such as the fuel yield, biomass price, grassroot costs and electricity price are deemed the most important, though with a different ranking with the plant layout.

For SNG plants with reforming, the wood price and bio-oil yield rank among the top three, followed by the electricity price, grassroot costs, by-product yield and sales price. The only exception is the 'SNG-RC-CA' case, where the power price has a moderate importance, as no electrical heating for the reforming reactor is required, and the total power demand is negligible (about $2 \%$ of the biomass LHV).

The high sensitivity to the SOEC and AEC specific costs for plants with electrolysis was demonstrated as well when performing the Morris screening. The operating lifetime is one of the three most sensitive parameters, likely because it affects simultaneously the total production of each fuel, the annual capital repayment, operating and maintenance costs and total capital costs. In particular, a variation of the plant life may lead to higher costs of the electrolysis system and thus of the total capital expenses, because SOEC stacks should be substituted and fully replaced every 10 years.

The electricity cost is the fourth most sensitive parameter in plants producing $\mathrm{H}_{2}$ or $\mathrm{MeOH}$ and is generally ranked higher than in plants producing SNG. This difference is likely due to the higher power consumption, which amounts to $2-20 \%$ of the biomass heating rate (LHV) for SNG plants, and to 23$39 \%$ for $\mathrm{H}_{2}$ and $\mathrm{MeOH}$ ones. The grassroot costs also rank higher in the case of MeOH plants with reforming, which can be explained by the higher installation costs of a $\mathrm{MeOH}$ compression and synthesis train. Moreover, high sensitivity to the by-product price is found for these plants, which can be explained by the large historical variability of the $\mathrm{MeOH}$ price over the last 10 years (from around $\$ 200$ to $\$ 600$ per 
tonne).

As suggested in Morris[57], parameters with low $\mu^{*}$ and low $\sigma$ are deemed as non-influential, and the screening indicates that the discount rate, tax level and catalyst price have little impact on the final MFSP. In other words, investing in better or more expensive catalysts is worthy if that leads to a greater bio-oil yield.

\subsubsection{Regression analysis}

A multi-variable regression analysis was performed, based on Monte-Carlo simulations, to model the relationship between the minimum fuel selling prices and the various input variables (e.g. power price, biomass cost, etc.). The coefficient of determination was higher than $70 \%$ in all cases, ranging between $78 \%$ and $94 \%$, which means that all models can be expressed satisfactorily by a linear relationship (Figure 9 ). The results are in good agreement with experience-based knowledge and most findings from the local sensitivity and Morris screening approaches.

High sensitivity of the fuel selling price to a given parameter corresponds to a high $\beta^{2}$ factor - a value of 1 implying a perfect linear correlation. For example, for the layout 'SNG-R-C-CA', the $\beta^{2}$ coefficient for the biomass cost is about 0.46 , while it is about 0.29 for the bio-oil yield, meaning that the MFSP is more sensitive to the first parameter than to the latter. For nearly all polygeneration concepts, the two most sensitive factors are the bio-oil yield and wood price. The fuel yield is the first sensitive parameter for the standard hydropyrolysis system, which can be expected as it is the only product from this plant. The electricity cost is deemed influential only in plants with electrolysis or with electrical heating for reforming.

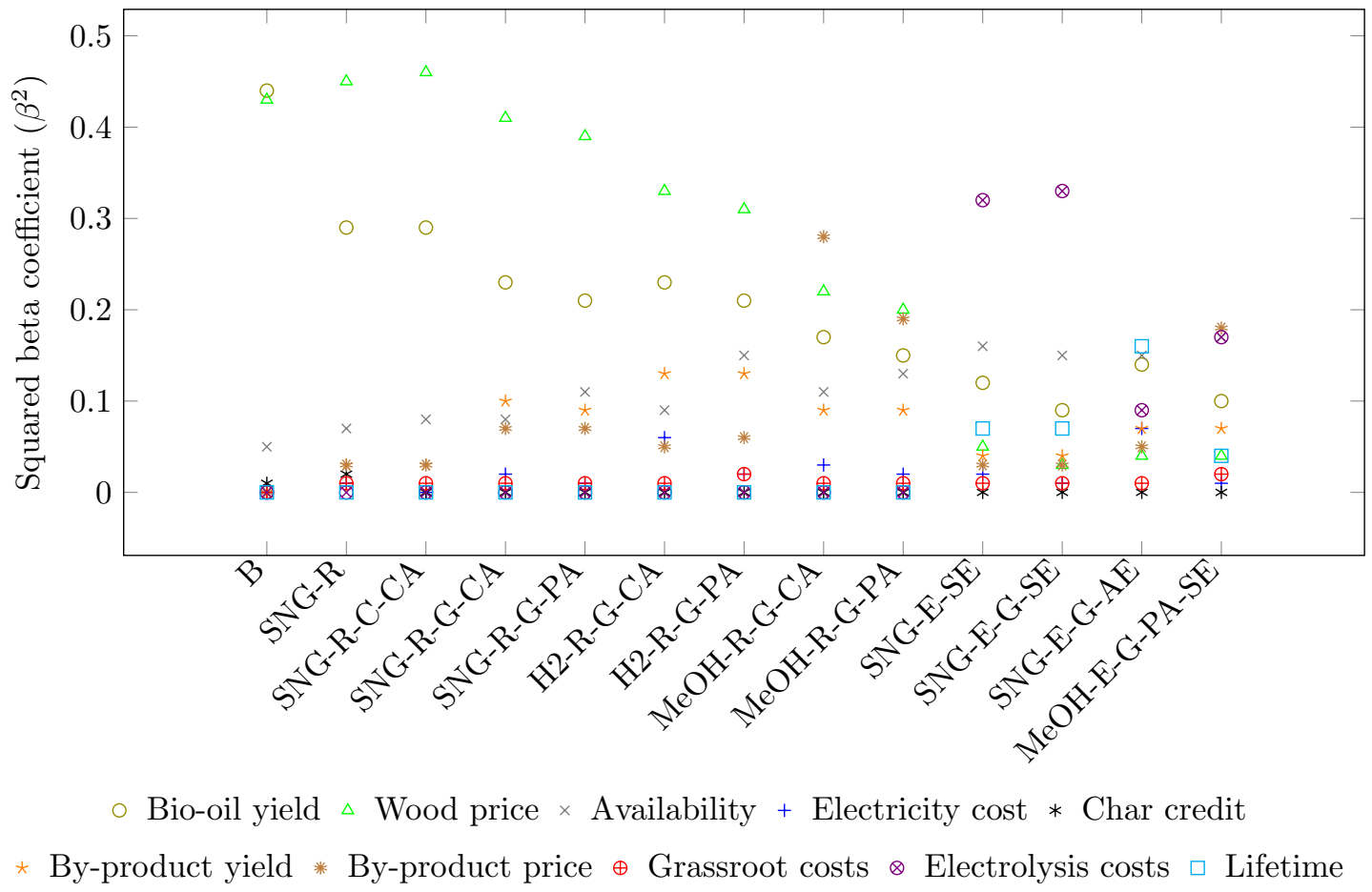

Figure 9: Sensitive parameters for each polygeneration layout, ranked based on their $\beta^{2}$ coefficients through multi-variable regression analysis. Only parameters with a $\beta^{2}$ coefficient higher than $1 \%$ are shown.

The main difference lies in the importance given to the plant availability (number of operating hours per year), which is ranked first when carrying out a Morris screening, and only second to fourth when performing the regression analysis. In addition, the plant lifetime was seen as non-influential in the regression analysis for plants with steam reforming, whilst it was ranked as the third to fifth most critical parameter in the 
Morris screening. These discrepancies are most likely due to the mode of generating samples and calculating the output variances, and this aspect is further discussed.

As indicated with the Morris screening, low plant lifetimes can critically impact the plant profitability. However, in reality, as shown with the linear regressions, this is unlikely to affect significantly the production costs, as state-of-the-art biomass-to-fuel plants have an operating lifetime of 25 to 30 years, with few differences across plants. The same considerations can be drawn regarding the plant availability: it can, in theory, vary from 0 to 8760 hours per year, but is most likely to range between 7500 and 8760 for well-built facilities. The sensitivity of the MFSPs to these parameters was therefore deemed lower when applying a regression analysis on the Monte-Carlo simulations.

\subsection{Uncertainty analysis}

A preliminary economic analysis builds on fixed parameter values (process performance and economic conditions) for any estimation of the capital, production and selling prices, while a sensitivity analysis generally considers a uniform variability of the input parameters. Parameters such as the biomass price, grassroot costs and by-product credits are subjected to both high variability and uncertainty. It is thus essential to assign a range of values and probability distribution to each uncertain parameter to evaluate the risks of each polygeneration concept. The Monte-Carlo simulations account for these uncertainties, and the probability density functions of the minimum fuel selling price can be approximated for each plant layout using high numbers of samples.

The cumulative density functions (Figure 10) and box-whisker plots (Figure 11) show the large range of possible cost values for each polygeneration concept. For plants with internal hydrogen generation, the minimum selling prices vary from $\$-0.4$ to $\$ 7.1$ (\$-3 to 57) per gallon (per GJ), with SNG plants ranking better than $\mathrm{H}_{2}$ plants, and those performing better than $\mathrm{MeOH}$ layouts. The negative values illustrate that, in some economic scenarios with high by-product yield, low grassroot, biomass and power prices, the revenues generated by the sales of SNG and $\mathrm{H}_{2}$ may outweigh the total production costs. However, these cases correspond to extremely favourable scenarios, and have a probability to occur smaller than $0.1 \%$.

The implementation of electrolysis is associated with greater risks - the investment costs of SOECs and AECs are generally higher than of reforming processes, and display higher uncertainty because of their level of technological maturity. The MFSPs for such polygeneration plants vary between $\$-2.1$ and $\$ 27$ per gallon, which corresponds to an uncertainty range nearly three times larger than of plants without electrolysis, and about four times larger than of conventional hydropyrolysis systems. However, electrically heated reformers are novel technologies, are currently not available commercially, and the uncertainty associated with their costs may be underestimated $(\simeq 30 \%)$.

On the one hand, polygeneration plants with SNG or $\mathrm{H}_{2}$ production, with reforming, are highly likely (probability higher than $95 \%$ ) to be more profitable (lower MFSPs) than a single-product hydropyrolysis plant. Plants with $\mathrm{MeOH}$ production are associated with slightly higher risks because of the high uncertainty associated with the sales price of this by-product. On the other hand, these numbers fall to 1-15\% when comparing the standard hydropyrolysis system to electrolysis plants, which may discourage further investments in the latter. These figures also illustrate the potential economic benefits when multiple products are generated instead of a single fuel. They demonstrate the larger uncertainty for plants producing hydrogen and methanol, and for those with electrolysis, since the confidence intervals of these concepts are larger than of the conventional hydropyrolysis system.

A direct comparison between the price of conventional transport fuels, such as diesel and gasoline, and bio-oil generated from hydropyrolysis is difficult. Firstly, the fuel prices vary significantly over time and are subject to various taxes (e.g. value-added and green taxes) that greatly differ across countries, even when considering only the European Union. Secondly, the minimum selling price calculated in this work corresponds to a NPV over the plant life of 0 , which is not sufficient to justify an investment in such technologies. Thirdly, a corporate tax rate of $22 \%$ was assumed - it is the current Danish value [52], but is far lower than the total taxes imposed on transportation fuels [56]. In general, more than half of the automotive fuel price is tax-based, and tax reductions for green fuels derived from hydropyrolysis may benefit from tax reductions/exemptions and subsidies. 


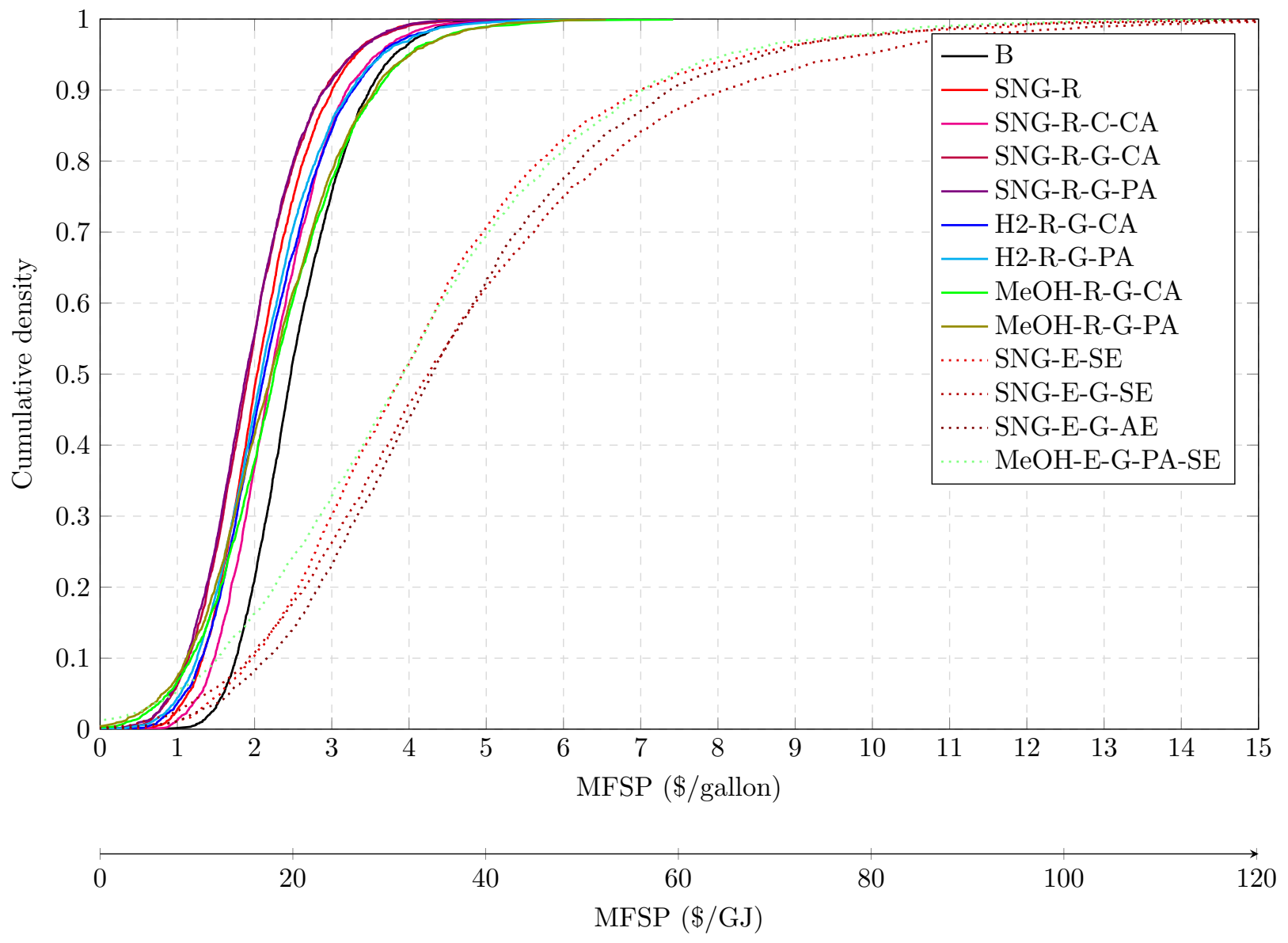

Figure 10: Cumulative density of the distribution function of the minimum fuel selling price (MFSP) for polygeneration layouts with hydropyrolysis 


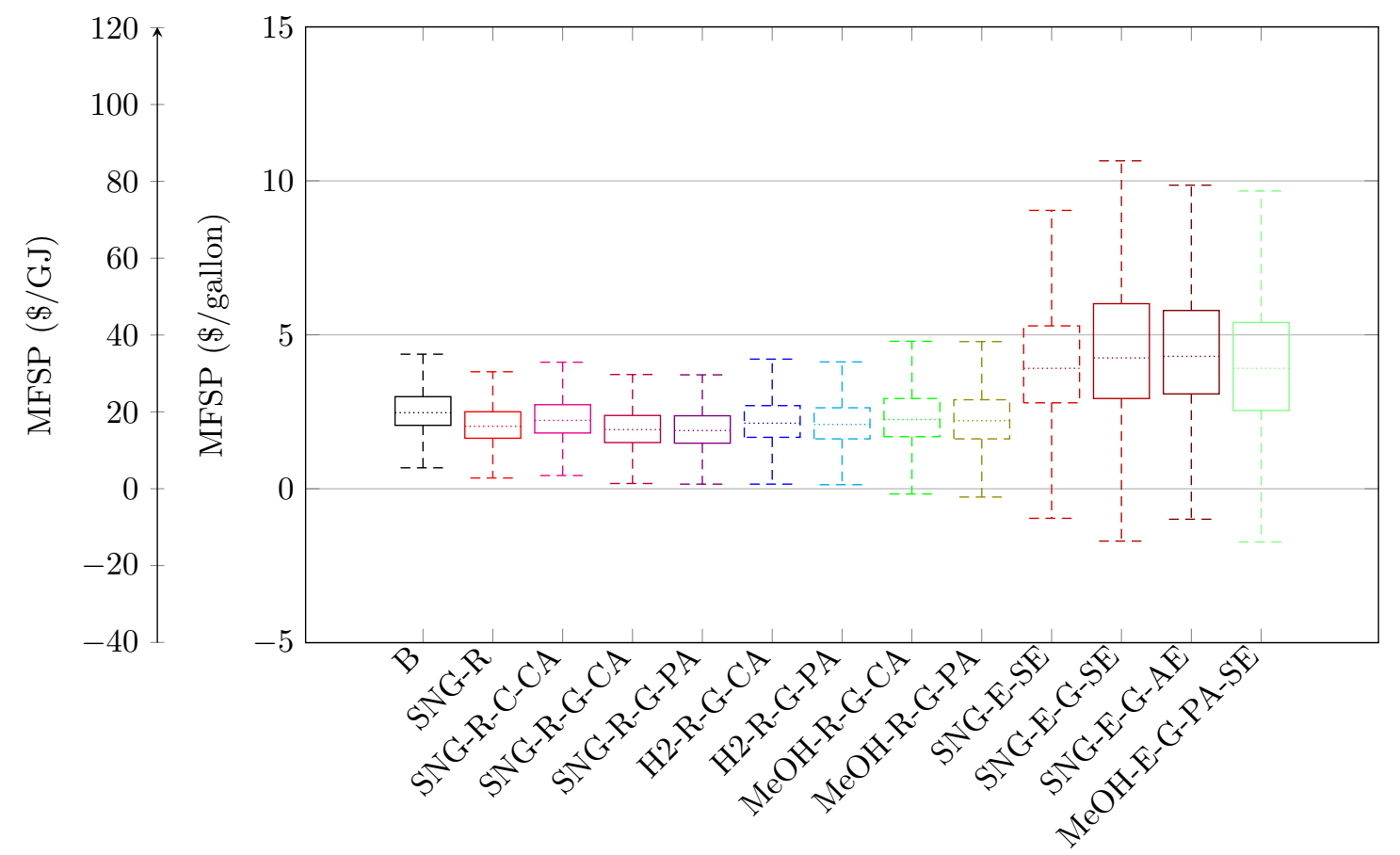

Figure 11: Tukey boxplot of the minimum fuel selling prices of bio-oil for the different polygeneration concepts under uncertainties

Excluding both tariffs and value-added taxes, the gasoline price across the European Union varies between $\$ 2.2$ (Slovenia) and $\$ 3.1$ (Sweden) per gallon, which may be compared to the range of MFSPs of $\$ 0.78-5.0$ for the standard hydropyrolysis system [68]. Assuming that the hydropyrolysis plant should be profitable (NPV of 0) after a discounted payback time of 5 years, this corresponds to a range of MFSPs of $\$ 0.9-5.5$ per gallon.

Assuming the same taxes for both fuels, bio-oil has a probability of being cheaper in $63 \%$ of the cases if the lower bound for gasoline price is considered and $95 \%$ if the upper bound is taken. These preliminary estimates suggest that bio-oil produced by hydropyrolysis may be competitive against petroleum-derived fuels, especially if those are subjected to higher taxes or if green fuels benefit from feed-in tariffs. However, based on the current economic context, biomass-derived fuels cannot compete with fossil-fuel gasoline.

\section{Discussion}

\subsection{Economic analysis}

A direct comparison with the results presented in the literature is difficult because each cost analysis of biomass-to-fuel systems considers different economic and financing assumptions. The most similar study is the techno-economic assessment of the standard hydropyrolysis plant presented in Tan et al.[18] for the $\mathrm{IH}^{2}$ process. The analysis was performed considering 2007 as base year, with a plant lifetime of 30 years, a $n$th plant assumption and following the Lang costing method. The same plant size (2000 tonnes per day of biomass) was assumed, and the authors found a total capital investment of about $\$ 263$ million, which should be compared with the figure of $\$ 220$ million in the present work. These differences are likely related to the different cost correlations, and to the values assumed for contingency (project and equipment) costs. However, both works conclude that the hydrogen plant always represents the major contributor to the total capital costs, followed by the hydropyrolysis system. The estimated minimum fuel selling prices range from $\$ 1.64$ to $\$ 1.87$ per gallon, which is lower than the estimated price of $\$ 2.44$ in the present study. 
Studies on fast pyrolysis are more numerous, and the values presented in such works are in the same order of magnitude than in the present work. However, caution should be exercised when comparing different biomass-to-liquids concepts. The total capital costs ranged from $\$ 37$ million [13] to $\$ 143$ million [14] for a 1000 tonnes per day capacity, and the minimum fuel sell prices from $\$ 0.41$ to $\$ 2.46$ per gallon. The study of Wright et al.[15] deals with the techno-economic assessment of fast pyrolysis of biomass to bio-oil, considering internal hydrogen generation (reforming) and external one (market purchase). They found out that the fuel product value would be around $\$ 3.09$ per gallon, which is about 15 to $33 \%$ higher than the present ones. More recently, Brown et al.[16] calculated a value of $\$ 2.57$ per gallon, using updated economic parameters, which is more in line with this work, and Li et al.[19] estimated this selling price to $\$ 4.20$ and $\$ 4.27$ per gallon. Dimitriou et al.[69] presented a techno-economic assessment of biomass-to-liquids concepts, without considering pyrolysis, and found investment costs between 397 and 537 million euros for a plant capacity of 2000 tonnes per day, which are significantly higher than the numbers presented in other works. Although these studies differ with respect to the feedstock price and other economic parameters, the capital costs of BTL designs with pyrolysis seem to be lower than of other layouts with gasification and Fischer-Tropsch technologies. The selling prices of these liquid fuels are therefore lower, and the MFSPs for bio-oil are generally found in the range of $\$ 2.5$ to $\$ 4$ per gallon, with the lowest values reached with hydropyrolysis.

\subsection{Sensitivity analyses}

The local and global sensitivity approaches applied in this work return results that were, in general, in agreement with each other, and with the findings presented in the literature. For example, Tan et al.[18] also highlighted the high sensitivity of the MFSP to the feedstock cost, total capital investment, and total yield of the liquid fuels. They also emphasized the small influence of the catalyst costs, interest rate and byproduct (only char and steam) credits. The same conclusions were drawn by Wright et al.[15], who compared different scenarios for bio-oil production from fast pyrolysis. However, they found that the MFSPs are more sensitive to the fixed capital costs than to the bio-oil yield, which is in contrast to other studies.

To the knowledge of the authors, no other study included and compared the results from various sensitivity analysis methods (local and global). Although the same factors (wood price, bio-oil yield, plant availability, electrolysis investment costs and power prices) were identified in biomass-to-liquid studies, some parameters were ranked differently, whilst some others were deemed negligible.

For instance, the plant lifetime was identified as an important parameter in the Morris screening method, while it was deduced as non-influential when applying a multi-variable linear regression analysis or a local sensitivity. In one-factor-at-a-time designs, as used in local sensitivity analyses, each parameter takes a number of finite values, and each value is equally present. The effect of variations in the plant lifetime may be overestimated compared to reality, as it was assumed this parameter could take, in an equally probable way, any value between 15 and 40 years. On the contrary, this multi-variable regression analysis builds on a sample of lifetime values following a $\beta$-distribution, with most of the values comprised between 25 and 30 years. As this range is much smaller, the variance of the MFSPs attributable to the plant lifetime is reduced.

In summary, the Morris screening approach is a powerful tool for assessing non-linear effects and identifying sensitive parameters if no reasonable assumptions can be drawn regarding their probability distribution, but it may overestimate the importance of some. Linear regression analyses are the most accurate sensitivity tools, as they build on parameter samples derived from their probability distributions. However, they are limited to models with high coefficients of determination, and may lead to erroneous conclusions if appropriate probability distributions were not derived at first. It is thus recommendable to apply both types of approaches in further analyses.

\subsection{Uncertainty analysis}

Even fewer works dealt with the uncertainty analysis of biomass-to-liquids systems, one of the most recent one being the work of Dimitriou et al.[69]. They conducted a techno-economic analysis of biomass-toliquid concepts, with a focus on pressurised gasification, Fischer-Tropsch synthesis and methanol conversion. 
Although the results are not directly comparable, since the investigated processes were different - there were neither hydropyrolysis nor electrolysis systems in their case - the employed methodology was similar and built on Monte-Carlo simulations. Only ten uncertain input parameters were selected, the most important ones being the biomass cost, installed costs, operating costs, number of operating hours and total fuel energy output. They also compared the cumulative probability of biofuel production costs of each concept to the conventional transport fuel prices. They emphasized the large range of possible values of the biofuel production costs (from a factor one to three), but concluded that the probability of such fuels to be cheaper than conventional ones is smaller than $10 \%$, which is a lower value than the ones found in the present work. These differences may result from the selection of the uncertainty ranges for the electricity price and electrolysis cells, which correspond to the lower ends of estimates found in the scientific literature.

\section{Conclusion}

The present work investigated the techno-economic feasibility of polygeneration systems for the production of bio-oil and other fuels (SNG, $\mathrm{H}_{2}$ and $\mathrm{MeOH}$ ) based on hydropyrolysis. Thirteen layouts were developed with the process simulation software DNA and Aspen Plus in a previous study by the same authors, and the retrieved process data was used for further component and process sizing.

The overall energy efficiency of these hydropyrolysis concepts ranges from $61 \%$ (LHV) in the standard case, without additional fuel generation, to up to $89 \%, 81 \%$ and $76 \%$ when co-producing SNG, $\mathrm{H}_{2}$ and $\mathrm{MeOH}$. For a biomass capacity of 2000 tonnes per day, the total capital costs ranged from $\$ 180$ to $\$ 620$ million. The plant designs with SNG production and reforming have the smallest grassroot costs, whilst those with $\mathrm{MeOH}$ generation and electrolysis have the highest, because of the high installation cost of SOECs and AECs.

The resulting production costs vary between $\$ 17$ and $\$ 24$ per GJ of valuable products, of which the biggest share is the feedstock and electricity costs (55-60\%), followed by the annualised investment expenses (15-20\%). The maintenance and other manufacturing expenses contribute to the remaining $20-25 \%$. The biomass cost is the major source of expenses for SNG/MeOH plants with reforming, while the electricity cost is the major one for $\mathrm{H}_{2}$ layouts and $\mathrm{SNG} / \mathrm{MeOH}$ plants with electrolysis.

The minimum fuel selling prices were calculated considering the possible incomes from the generation of by-products (char, process steam, chemical fuel) and tax reduction because of plant depreciation. Based on the current market prices of green $\mathrm{SNG}, \mathrm{H}_{2}$ and $\mathrm{MeOH}$, all polygeneration concepts, except the one with alkaline electrolysis, may achieve smaller MFSPs (down to $\$ 14$ per GJ) than the standard hydropyrolysis system (about $\$ 21$ per GJ), which illustrates the potential benefits of generating multiple products from biomass. These numbers are highly sensitive to the variability in the biomass cost, power price, plant lifetime and availability, bio-oil and by-product yield and value, as well as grassroot costs.

Based on the uncertainty analyses, hydropyrolysis plants with SNG and $\mathrm{H}_{2}$ cogeneration were found to be the most robust and profitable concepts. They possibly achieve fuel costs that would make them competitive against conventional petroleum-derived fuels ( $\$ 5$ to 30 per GJ). Concepts with electrolysis were found to have large deviations around a mean value of $\$ 30$ to 40 per GJ, which may discourage the implementation of such facilities without subsequent tax reductions and green credits.

\section{Acknowledgements}

This work is part of the H2CAP project (Hydrogen assisted catalytic pyrolysis for green fuels). It is supported by The Danish Council for Strategic Research (now Innovation Fund Denmark, project 137700025A), The Programme Commission on Sustainable Energy and Environment. Riccardo Bergamini and Fabian Bühler from the Technical University of Denmark are thanked for the technical support when implementing the sensitivity and uncertainty routines. 


\section{Appendix A. Technical performance of polygeneration systems}

\section{Appendix A.1. Performance indicators}

The performance of each layout depends on the efficiency of each process operation and on the overall system integration. The system efficiency $\eta_{\text {system }}$ (Equation A.1) is defined as the ratio of the useful energy outputs (e.g. chemical energy of bio-oil and fuels) to the necessary energy inputs (e.g. chemical energy of biomass). The system efficiency includes the demands of hydrogen, power and heat, where the processes used to generate hydrogen and external heating are not accounted for.

$$
\eta_{\text {system }}=\frac{\Delta h_{\text {bio-oil }}^{0} \cdot \dot{m}_{\text {bio-oil }}+\Delta h_{\mathrm{SNG}}^{0} \cdot \dot{m}_{\mathrm{SNG}}+\Delta h_{\mathrm{H}_{2}, \text { produced }}^{0} \cdot \dot{m}_{\mathrm{H}_{2}, \text { produced }}+\Delta h_{\mathrm{MeOH}}^{0} \cdot \dot{m}_{\mathrm{MeOH}}}{\Delta h_{\text {biomass }}^{0} \cdot \dot{m}_{\text {biomass }}+\Delta h_{\mathrm{H}_{2} \text { external }}^{0} \cdot \dot{m}_{\mathrm{H}_{2}, \text { external }}+\dot{W}_{\text {external }}+\dot{Q}_{\text {external }}}
$$

where $\dot{m}, \Delta h^{0}, \dot{W}$ and $\dot{Q}$ are the mass flow rates, lower heating values, power and heat demands.

A total efficiency (Equation A.2) is defined: it considers the electrical losses in the upstream processes to generate the hydrogen and heat required on-site.

$$
\eta_{\text {total }}=\frac{\Delta h_{\text {bio-oil }}^{0} \cdot \dot{m}_{\text {bio-oil }}+\Delta h_{\mathrm{SNG}}^{0} \cdot \dot{m}_{\mathrm{SNG}}+\Delta h_{\mathrm{H}_{2}, \text { produced }}^{0} \cdot \dot{m}_{\mathrm{H}_{2}, \text { produced }}+\Delta h_{\mathrm{MeOH}}^{0} \cdot \dot{m}_{\mathrm{MeOH}}}{\Delta h_{\text {biomass }}^{0} \cdot \dot{m}_{\text {biomass }}+\dot{W}_{\text {total }}}
$$

If the produced char is not converted, both efficiencies will also be given with a term $\Delta h_{\text {char }}^{0} \cdot \dot{m}_{\text {char }}$.

Finally, a carbon conversion efficiency (Equation A.3) is derived $\left(X_{\mathrm{C}}\right)$, defined as the ratio of carbon present in the valuable outputs (e.g. bio-oil, $\mathrm{SNG}$ and $\mathrm{CH}_{3} \mathrm{OH}$ ) to the carbon introduced in the system with biomass:

$$
X_{\mathrm{C}}=\frac{x_{\mathrm{C}, \text { bio-oil }} \cdot \dot{m}_{\text {bio-oil }}+x_{\mathrm{C}, \mathrm{SNG}} \cdot \dot{m}_{\mathrm{SNG}}+x_{\mathrm{C}, \mathrm{MeOH}} \cdot \dot{m}_{\mathrm{MeOH}}}{x_{\mathrm{C}, \text { biomass }} \cdot \dot{m}_{\text {biomass }}}
$$

\section{Appendix A.2. Technical performance of polygeneration systems with SNG production}

The baseline hydropyrolysis concept has a negligible power demand, as all process units, except for the burner, operate at 22.4 bar. The system efficiency is about $61 \%$ if char is not included, and $76 \%$ otherwise. The carbon efficiency is about $49 \%$ if char is not included, and $63 \%$ otherwise. The performance of polygeneration systems with SNG production is presented in Table A.11. 
Table A.11: Performance of polygeneration systems with SNG production

\begin{tabular}{|c|c|c|c|c|c|c|c|}
\hline Layout & SNG-R & $\begin{array}{r}\text { SNG-R-C } \\
-\mathrm{CA}\end{array}$ & $\begin{array}{r}\text { SNG-R-G } \\
-\mathrm{CA}\end{array}$ & $\begin{array}{r}\text { SNG-R-G } \\
-\mathrm{PA}\end{array}$ & $\begin{array}{r}\text { SNG-E } \\
\text {-SE }\end{array}$ & $\begin{array}{r}\text { SNG-E-G } \\
-\mathrm{SE}\end{array}$ & $\begin{array}{r}\text { SNG-E-G } \\
-\mathrm{AE}\end{array}$ \\
\hline \multicolumn{8}{|l|}{ Pathway } \\
\hline Product & SNG & SNG & SNG & SNG & SNG & SNG & SNG \\
\hline $\mathrm{H}_{2}$ & $\mathrm{R}$ & $\mathrm{R}$ & $\mathrm{R}$ & $\mathrm{R}$ & $\mathrm{E}$ & $\mathrm{E}$ & $\mathrm{E}$ \\
\hline Char & - & $\mathrm{C}$ & G & G & - & G & G \\
\hline \multicolumn{8}{|l|}{ Technologies } \\
\hline $\mathrm{CO}_{2}$ & $\mathrm{CA}$ & $\mathrm{CA}$ & $\mathrm{CA}$ & PA & - & - & - \\
\hline Electrolysis & - & - & - & - & $\mathrm{SE}$ & $\mathrm{SE}$ & $\mathrm{AE}$ \\
\hline \multicolumn{8}{|l|}{ Inputs (MW) } \\
\hline Biomass & 100 & 100 & 100 & 100 & 100 & 100 & 100 \\
\hline Heat (reformer) & 9 & - & 11 & 11 & - & - & - \\
\hline Heat (others) & 4 & - & 6 & - & - & - & - \\
\hline Hydrogen & - & - & - & - & 49 & 63 & 63 \\
\hline Electricity & $2(15)$ & $2(2)$ & $3(20)$ & $3(15)$ & $0(51)$ & $0(66)$ & $0(117)$ \\
\hline \multicolumn{8}{|l|}{ Outputs (MW) } \\
\hline Bio-oil & 61 & 61 & 61 & 61 & 61 & 61 & 61 \\
\hline SNG & 18 & 18 & 31 & 31 & 59 & 83 & 83 \\
\hline Char & 15 & - & - & - & 15 & - & - \\
\hline \multicolumn{8}{|l|}{ Efficiency } \\
\hline$\eta_{\text {system }}$ & $68 \%$ & $77 \%$ & $77 \%$ & $81 \%$ & $79 \%$ & $89 \%$ & $89 \%$ \\
\hline$\eta_{\text {system,char }}$ & $81 \%$ & - & - & - & $91 \%$ & - & - \\
\hline$\eta_{\text {total }}$ & $68 \%$ & $77 \%$ & $77 \%$ & $81 \%$ & $79 \%$ & $88 \%$ & $67 \%$ \\
\hline$\eta_{\text {total,char }}$ & $81 \%$ & - & - & - & $89 \%$ & - & - \\
\hline$X_{\mathrm{C}}$ & $59 \%$ & $59 \%$ & $70 \%$ & $70 \%$ & $86 \%$ & $98 \%$ & $98 \%$ \\
\hline$X_{\mathrm{C}, \text { char }}$ & $73 \%$ & - & - & - & $100 \%$ & - & - \\
\hline
\end{tabular}


Appendix A.3. Technical performance of polygeneration systems with $\mathrm{H}_{2}$ and $\mathrm{MeOH}$ production

The performance of polygeneration systems with $\mathrm{H}_{2}$ or $\mathrm{MeOH}$ production is presented in Table A.12.

Table A.12: Performance of polygeneration systems with $\mathrm{H}_{2}$ and $\mathrm{MeOH}$ production

\begin{tabular}{|c|c|c|c|c|c|}
\hline Layout & $\begin{array}{r}\text { H2-R-G } \\
-C A\end{array}$ & $\begin{array}{r}\text { H2-R-G } \\
-\mathrm{PA}\end{array}$ & $\begin{array}{r}\mathrm{MeOH}-\mathrm{R}-\mathrm{G} \\
-\mathrm{CA}\end{array}$ & $\begin{array}{r}\mathrm{MeOH}-\mathrm{R}-\mathrm{G} \\
-\mathrm{PA}\end{array}$ & $\begin{array}{r}\mathrm{MeOH}-\mathrm{E}-\mathrm{G} \\
\text {-PA-SE }\end{array}$ \\
\hline \multicolumn{6}{|l|}{ Pathway } \\
\hline Product & $\mathrm{H}_{2}$ & $\mathrm{H}_{2}$ & $\mathrm{MeOH}$ & $\mathrm{MeOH}$ & $\mathrm{MeOH}$ \\
\hline $\mathrm{H}_{2}$ & $\mathrm{R}$ & $\mathrm{R}$ & $\mathrm{R}$ & $\mathrm{R}$ & $\mathrm{E}$ \\
\hline Char & G & G & G & G & G \\
\hline \multicolumn{6}{|l|}{ Technologies } \\
\hline $\mathrm{CO}_{2}$ & $\mathrm{CA}$ & PA & $\mathrm{CA}$ & PA & PA \\
\hline Electrolysis & - & - & - & - & $\mathrm{SE}$ \\
\hline \multicolumn{6}{|l|}{ Inputs (MW) } \\
\hline Biomass & 100 & 100 & 100 & 100 & 100 \\
\hline Heat (reformer) & 18 & 18 & 19 & 19 & 19 \\
\hline Heat (others) & 16 & - & 8 & - & - \\
\hline Hydrogen & - & - & - & - & 42 \\
\hline Electricity & $5(39)$ & $5(23)$ & $6(33)$ & $8(27)$ & $7(70)$ \\
\hline \multicolumn{6}{|l|}{ Outputs (MW) } \\
\hline Bio-oil & 61 & 61 & 61 & 61 & 61 \\
\hline Hydrogen & 37 & 37 & - & - & - \\
\hline Methanol & - & - & 33 & 33 & 68 \\
\hline \multicolumn{6}{|l|}{ Efficiency } \\
\hline$\eta_{\text {system }}$ & $71 \%$ & $81 \%$ & $71 \%$ & $74 \%$ & $78 \%$ \\
\hline$\eta_{\text {total }}$ & $71 \%$ & $81 \%$ & $71 \%$ & $74 \%$ & $76 \%$ \\
\hline$X_{\mathrm{C}}$ & $49 \%$ & $49 \%$ & $71 \%$ & $71 \%$ & $95 \%$ \\
\hline
\end{tabular}




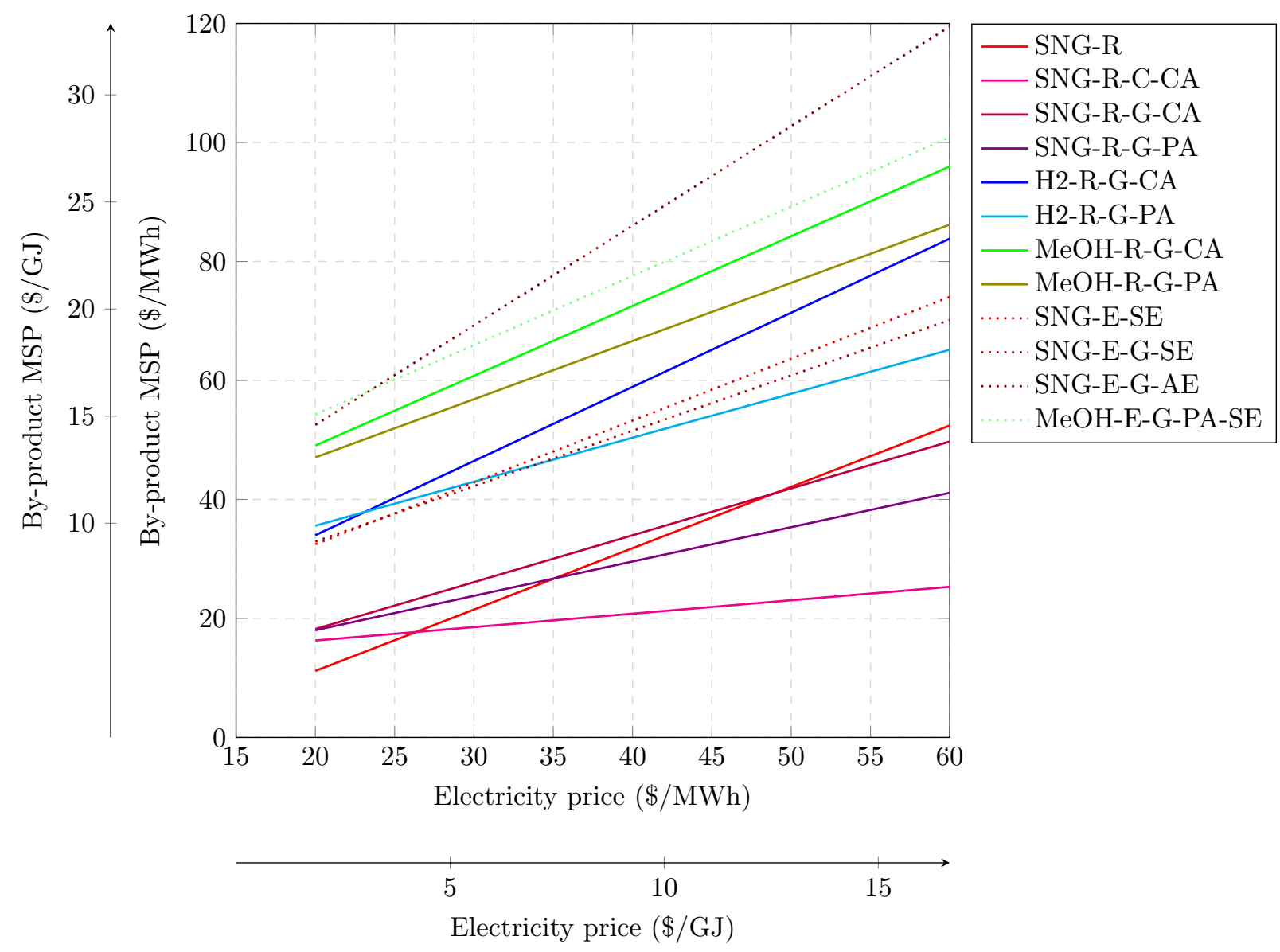

Figure B.12: Local sensitivity analysis of all concepts with variations of the electricity price, for a fixed bio-oil price of about $\$ 22$ per GJ 


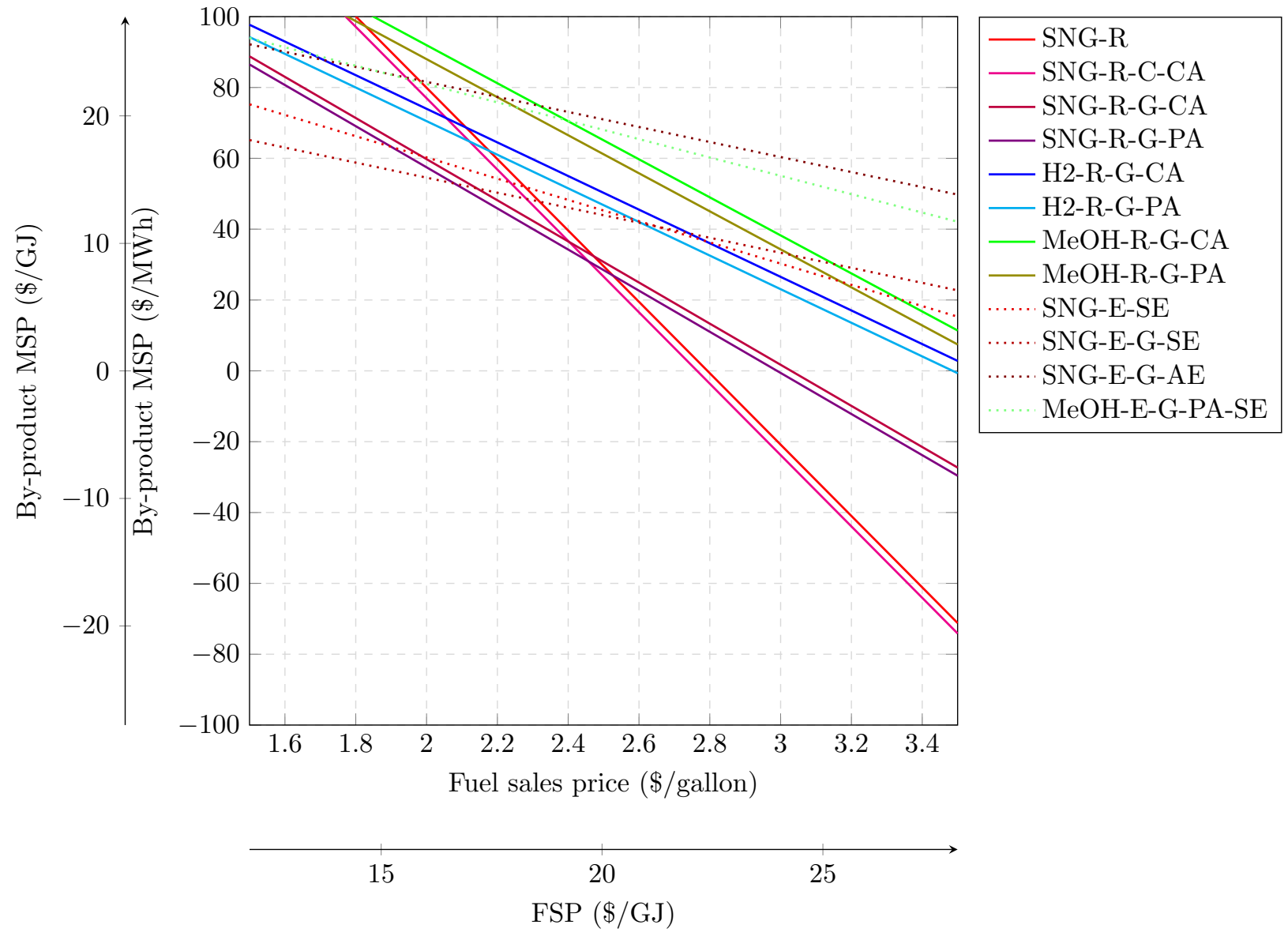

Figure B.13: Local sensitivity analysis of all concepts with variations of the minimum fuel selling price of the by-products for a fixed electricity price 


\section{Appendix C. Beta distributions}

Examples of samples for each $\beta$-distribution - power price, lifetime, yearly operation and SOEC investment cost (Figure C.14) are given in the following, based on 3000 simulations for the Monte-Carlo analysis.
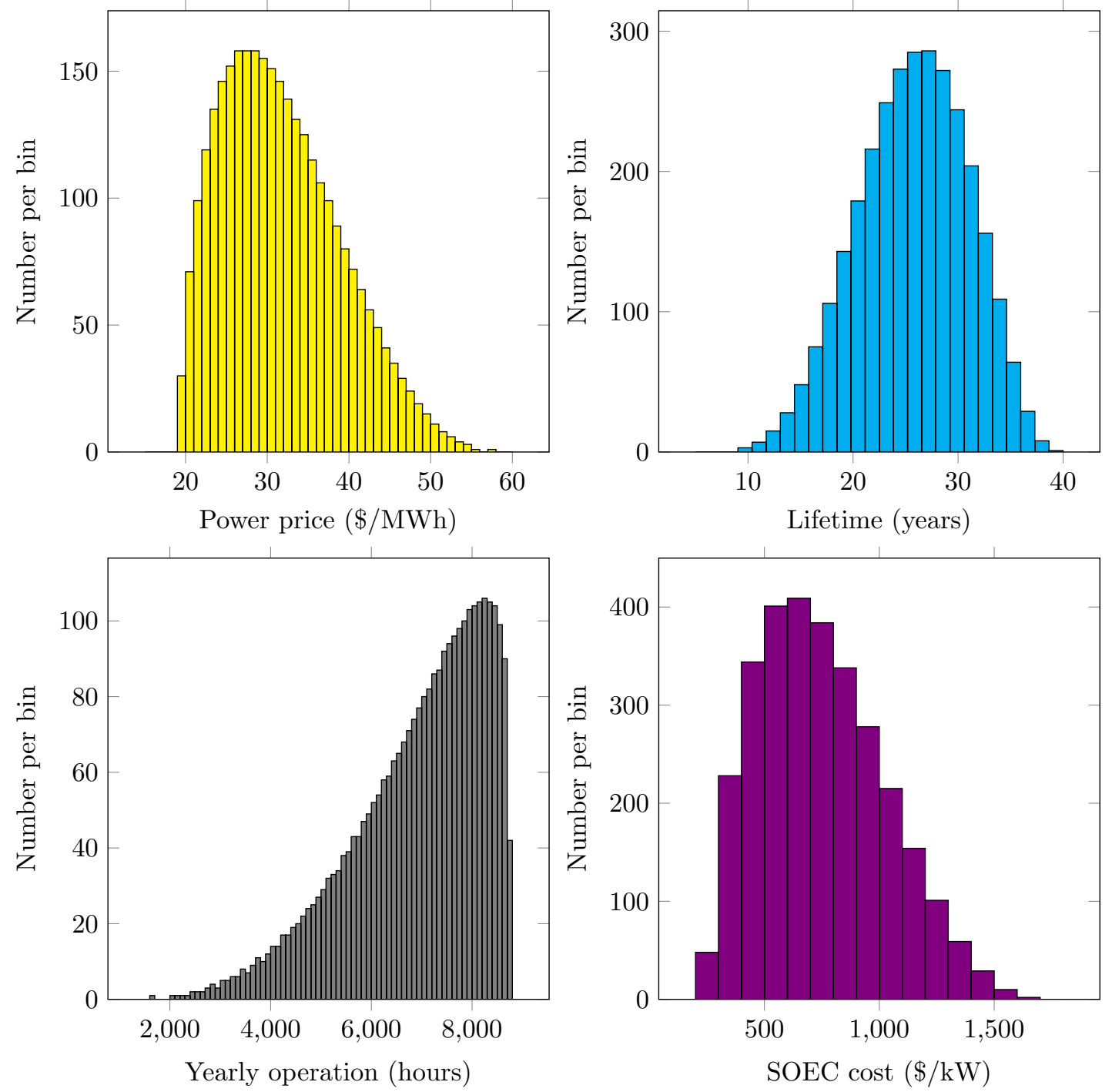

Figure C.14: Example of sample for the $\beta$-distribution of the electricity price, lifetime, yearly operation and SOEC cost (3000 simulations) 


\section{References}

[1] European Commission . EU action at international level - Transport. 2018. URL: https://ec.europa.eu/clima/policies/ international/paris_protocol/transport_en.

[2] International Transport Forum . Transport $\mathrm{CO}_{2}$ and the Paris Climate Agreement. 2018. URL: https://www.itf-oecd. org/sites/default/files/docs/transport-co2-paris-climate-agreement-ndcs.pdf.

[3] European Commission . EU Action - Climate strategies \& targets - 2030 climate \& energy framework. 2018. URL: https://ec.europa.eu/clima/policies/strategies/2030_en.

[4] Doornbosch, Richard and Steenblik, Ronald . BIOFUELS: IS THE CURE WORSE THAN THE DISEASE? Tech. Rep. SG/SD/RT(2007)3/REV1; Organisation for Economic Co-operation and Development; 2007. URL: https://www.oecd. org/sd-roundtable/39411732.pdf.

[5] Onel O, Niziolek AM, Floudas CA. Integrated biomass and fossil fuel systems towards the production of fuels and chemicals: state of the art approaches and future challenges. Current Opinion in Chemical Engineering 2015;9:66-74.

[6] Linck M, Felix L, Marker T, Roberts M. Integrated biomass hydropyrolysis and hydrotreating: a brief review. Wiley Interdisciplinary Reviews: Energy and Environment 2014;3(6):575-81.

[7] Resende FL. Recent advances on fast hydropyrolysis of biomass. Catalysis Today 2016;269:148-55.

[8] Balagurumurthy B, Oza TS, Bhaskar T, Adhikari DK. Renewable hydrocarbons through biomass hydropyrolysis process: challenges and opportunities. Journal of Material Cycles and Waste Management 2013;15(1):9-15.

[9] Pattiya A, Titiloye JO, Bridgwater AV. Fast pyrolysis of cassava rhizome in the presence of catalysts. Journal of Analytical and Applied Pyrolysis 2008;81(1):72-9.

[10] Agrawal R, Agrawal M, Singh N. Process for producing liquid hydrocarbon by pyrolysis of biomass in presence of hydrogen from a carbon-free energy source. 2012.

[11] Marker T, Felix L, Linck M. Hydropyrolysis of biomass for producing high quality fuels. 2013.

[12] Venkatakrishnan VK, Degenstein JC, Smeltz AD, Delgass WN, Agrawal R, Ribeiro FH. High-pressure fast-pyrolysis, fasthydropyrolysis and catalytic hydrodeoxygenation of cellulose: production of liquid fuel from biomass. Green Chemistry 2014;16(2):792-802.

[13] Islam MN, Ani FN. Techno-economics of rice husk pyrolysis, conversion with catalytic treatment to produce liquid fuel. Bioresource Technology 2000;73(1):67-75.

[14] Solantausta Y, Beckman D, Bridgwater A, Diebold J, Elliott D. Assessment of liquefaction and pyrolysis systems. Biomass and Bioenergy 1992;2(1-6):279-97.

[15] Wright MM, Daugaard DE, Satrio JA, Brown RC. Techno-economic analysis of biomass fast pyrolysis to transportation fuels. Fuel 2010;89:S2-.

[16] Brown TR, Thilakaratne R, Brown RC, Hu G. Techno-economic analysis of biomass to transportation fuels and electricity via fast pyrolysis and hydroprocessing. Fuel 2013;106:463-9.

[17] Marker TL, Felix LG, Linck MB, Roberts MJ. Integrated hydropyrolysis and hydroconversion (ih2) for the direct production of gasoline and diesel fuels or blending components from biomass, part 1: Proof of principle testing. Environmental Progress \& Sustainable Energy 2012;31(2):191-9.

[18] Tan EC, Marker TL, Roberts MJ. Direct production of gasoline and diesel fuels from biomass via integrated hydropyrolysis and hydroconversion process - a techno-economic analysis. Environmental Progress \& Sustainable Energy 2014;33(2):60917 .

[19] Li B, Ou L, Dang Q, Meyer P, Jones S, Brown R, et al. Techno-economic and uncertainty analysis of in situ and ex situ fast pyrolysis for biofuel production. Bioresource technology 2015;196:49-56.

[20] Nguyen TV, Clausen LR. Thermodynamic analysis of polygeneration systems based on catalytic hydropyrolysis for the production of bio-oil and fuels. Energy Conversion and Management 2018;171:1617-38.

[21] Elmegaard B, Houbak N. DNA - A General Energy System Simulation Tool. In: Amundsen J, editor. Proceedings of SIMS 2005 - 46th Conference on Simulation and Modeling. Trondheim, Norway: Tapir Academic Press; 2005, p. 43-52.

[22] Aspen Technology . Aspen Plus - Modelling Petroleum Processes. Burlington, USA: Aspen Technology; 1999.

[23] Marker T, Roberts M, Linck M, Felix L, Ortiz-Toral P, Wangerow J, et al. Biomass to gasoline and diesel using integrated hydropyrolysis and hydroconversion. Tech. Rep.; Gas Technology Inst., Des Plaines, IL (United States); 2013.

[24] Gassner M, Maréchal F. Thermo-economic optimisation of the integration of electrolysis in synthetic natural gas production from wood. Energy 2008;33(2):189-98.

[25] Jensen SH, Larsen PH, Mogensen M. Hydrogen and synthetic fuel production from renewable energy sources. International Journal of Hydrogen Energy 2007;32(15):3253-7.

[26] Laguna-Bercero M. Recent advances in high temperature electrolysis using solid oxide fuel cells: A review. Journal of Power Sources 2012;203:4-16.

[27] Gassner M, Maréchal F. Thermo-economic process model for thermochemical production of synthetic natural gas (sng) from lignocellulosic biomass. Biomass and Bioenergy 2009;33(11):1587-604.

[28] Tock L, Gassner M, Maréchal F. Thermochemical production of liquid fuels from biomass: Thermo-economic modeling, process design and process integration analysis. Biomass and Bioenergy 2010;34(12):1838-54.

[29] Radgen P, Cremer C, Warkentin S, Gerling P, May F, Knopf S. Verfahren zur co2-abscheidung und-speicherung. Studie im Auftrag des Umweltbundesamts UBA, Forschungsbericht 2006;20341110.

[30] Chen CC, Song Y. Generalized Electrolyte-NRTL Model for Mixed-Solvent Electrolyte Systems. AIChE Journal $2004 ; 50(8): 1928-41$.

[31] Soave G. 20 years of Redlich-Kwong equation of state. Fluid Phase Equilibria 1993;82:345-59. 
32] Gross J, Sadowski G. Perturbed-chain SAFT: An equation of state based on a perturbation theory for chain molecules. Industrial \& engineering chemistry research 2001;40(4):1244-60.

[33] Higman C. Gasification. In: Combustion Engineering Issues for Solid Fuel Systems. Elsevier; 2008 , p. 435.

[34] Mills GA, Steffgen FW. Catalytic methanation. Catalysis Reviews 1974;8(1):159-210.

[35] Hamelinck CN, Faaij AP. Future prospects for production of methanol and hydrogen from biomass. Journal of Power Sources 2002;111(1):1-22.

[36] Peduzzi E, Tock L, Boissonnet G, Maréchal F. Thermo-economic evaluation and optimization of the thermo-chemical conversion of biomass into methanol. Energy 2013;58:9-16.

[37] Turton R, Bailie R, Whiting W, Shaeiwitz J, Bhattacharyya D. Analysis, Synthesis and Design of Chemical Processes. Prentice Hall International Series in the Physical and Chemical Engineering Sciences; 4th ed.; Prentice Hall; 2012.

[38] Ulrich GD, Vasudevan PT. Chemical engineering: process design and economics; a practical guide. Process Publ.; 2004.

[39] Peters MS, Timmerhaus KD, West RE, Timmerhaus K, West R. Plant design and economics for chemical engineers; vol. 4. McGraw-Hill New York; 1968.

[40] Hamelinck CN, Faaij AP, den Uil H, Boerrigter H. Production of FT transportation fuels from biomass; technical options, process analysis and optimisation, and development potential. Energy 2004;29(11):1743-71.

[41] Energinet. Technology data for Renewable Fuels. Tech. Rep.; Energistyrelsen; 2018.

[42] Larson ED, Jin H, Celik FE. Large-scale gasification-based coproduction of fuels and electricity from switchgrass. Biofuels, Bioproducts and Biorefining 2009;3(2):174-94.

[43] Nielsen M, Rasmussen TØ. The Danish subsidy scheme for the use of biogas. Tech. Rep.; Energistyrelsen; 2018.

[44] Methanex Corporation . Methanex Monthly Average Regional Posted Contract Price History. 2018. URL: www .methanex . com/our-business/pricing.

[45] Nordpool Group . Historical Market Data. Online; 2018. URL: http://www.nordpoolgroup.com/ historical-market-data/.

[46] Bang C, Vitina A, Gregg JS, Lindboe HH. Analysis of biomass prices - future danish prices for straw, wood chips and wood pellets. Tech. Rep.; EA Energy Analyses; 2013.

[47] Lazard Ltd. . Lazard's levelized cost of energy analysis. Tech. Rep.; Lazard; 2018. URL: https://www.lazard.com/media/ 450773/lazards-levelized-cost-of-energy-version-120-vfinal.pdf.

[48] ForskNG . Biogas - SOEC Electrochemical upgrading of biogas to pipeline quality by means of SOEC electrolysis. Tech. Rep.; Haldor Topsøe; 2012.

[49] Penner S. Steps toward the hydrogen economy. Energy 2006;31(1):33-43.

[50] James BD, De Santis DA, Saur G. Hydrogen Production Pathways Cost Analysis (2013-2016). Tech. Rep.; DOE-Strategic Analysis-6231-1. Strategic Analysis Inc.; 2016.

[51] Danmarks Statistisks, DST . Priser og forbrug, forbrugpriser. 2018. URL: https://www.dst.dk/en/Statistik/emner/ priser-og-forbrug/forbrugerpriser.

[52] Skatterministeriet, SKAT . Din virksomheds skatteforhold. 2018. URL: https://www . skat.dk/skat .aspx?oid=2662.

[53] Sin G, Gernaey KV. Improving the morris method for sensitivity analysis by scaling the elementary effects. In: Computer Aided Chemical Engineering; vol. 26. Elsevier; 2009, p. 925-30.

[54] Iooss B, Lemaître P. A review on global sensitivity analysis methods. In: Uncertainty management in simulationoptimization of complex systems. Springer; 2015, p. 101-22.

[55] Eurostat. Electricity price statistics. 2018. URL: https://ec.europa.eu/eurostat/statistics-explained/index.php/ Electricity_price_statistics\#Electricity_prices_for_non-household_consumers.

[56] European Commission . Energy prices and costs in Europe. Tech. Rep. SWD(2016) 420 final; The European parliament, the Council, the European Economic and Social Committee and the Committee of the Regions; 2016. URL: https: //ec.europa.eu/energy/sites/ener/files/documents/com_2016_769.en_.pdf.

[57] Morris MD. Factorial sampling plans for preliminary computational experiments. Technometrics 1991;33(2):161-74.

[58] Campolongo F, Cariboni J, Saltelli A. An effective screening design for sensitivity analysis of large models. Environmental modelling \& software 2007;22(10):1509-18.

[59] Sin G, Gernaey KV, Lantz AE. Good modeling practice for pat applications: Propagation of input uncertainty and sensitivity analysis. Biotechnology progress 2009;25(4):1043-53.

[60] Metropolis N, Ulam S. The monte carlo method. Journal of the American statistical association 1949;44(247):335-41.

[61] Helton JC, Davis FJ. Latin hypercube sampling and the propagation of uncertainty in analyses of complex systems. Reliability Engineering \& System Safety 2003;81(1):23-69.

[62] Sin G, Gernaey K. Data handling and parameter estimation. Experimental Methods in Wastewater Treatment 2016;:20134.

[63] Dykes, Katherine L and Hand, MM and Lantz, Eric J and Stehly, Tyler J and Robinson, Michael C and Veers, Paul S and Tusing, Richard . Enabling the SMART Wind Power Plant of the Future Through Science-Based Innovation. Tech. Rep.; National Renewable Energy Laboratory (NREL); 2017.

[64] Bertuccioli L, Chan A, Hart D, Lehner F, Madden B, Standen E. Development of water electrolysis in the European Union. Tech. Rep.; E4tech Sarl with Element Energy Ltd for the Fuel Cells and Hydrogen Joint Undertaking; 2014.

[65] Mathiesen, Brian Vad and Skov, Iva Ridjan and Connolly, David and Nielsen, Mads Pagh and Vang Hendriksen, Peter and Bjerg Mogensen, Mogens and Højgaard Jensen, Søren and Dalgaard Ebbesen, Sune . Technology data for high temperature solid oxide electrolyser cells, alkali and PEM electrolysers. Tech. Rep; Aalborg University; 2013.

[66] EA Energy Analyses . Technology Data for Hydrogen Technologies. Tech. Rep.; EA Energy Analyses; 2016.

[67] Danish Energy Agency (Energistyrelsen), ENS . Teknologineutralt udbud 2018 afgjort (in Danish). 2018. URL: https: //presse.ens.dk/news/teknologineutralt-udbud-2018-afgjort-336739?utm_campaign=send_list. 
[68] European Environment Agency . Transport fuel prices and taxes. 2018. URL: https://www.eea.europa.eu/ data-and-maps/indicators/fuel-prices-and-taxes/assessment-7.

[69] Dimitriou I, Goldingay H, Bridgwater AV. Techno-economic and uncertainty analysis of biomass to liquid (btl) systems for transport fuel production. Renewable and Sustainable Energy Reviews 2018;88:160-75. 